\title{
(4)
}

UNIVERSIDAD PERUANA DE CIENCIAS APLICADAS

ESCUELA DE POSTGRADO

PROGRAMA DE MAESTRÍA EN ADMINISTRACIÓN DE EMPRESAS

La Perspectiva de Género en las Instituciones y Políticas Públicas

\section{TRABAJO DE INVESTIGACIÓN}

Para optar el grado académico de Maestro en Administración de Empresas

\section{AUTOR}

García Herrera, Jésica (0000-0002-6422-2927)

\section{ASESOR}

Cárdenas Solis, Celia Hermelinda (0000-0002-0013-8179) 
DEDICATORIA

Este trabajo de Investigación, lo dedico en primer lugar a mi amada madre, que es la que me impulsa y motiva todo el tiempo a ser una mejor persona, también a mi esposo e hijos que son mi mayor bendición y alegría y a quienes dedicaré siempre lo mejor de mi vida. 


\section{AGRADECIMIENTOS}

Quisiera agradecer a mi madre, por todo lo que ha he hecho y hace por sus hijos, hijas y familia, ella es el pilar de la familia y su ejemplo de valentía, amor y don de gente es lo que guía siempre mi vida.

Agradecer a mi esposo amado Manuel, por su apoyo incondicional y constante en todos los momentos de mi vida, juntos hemos construido una familia hermosa y valiosa y mi amor hacia él, como siempre le digo, es cada día más grande.

Agradezco a mis amados hijos Jonathan y Camila, quienes son la mejor y más grande motivación en mi vida, son los autores de mi felicidad, seres maravillosos, buenos y nobles por quienes siento el más grande amor y orgullo y agradezco a Dios y a la vida por ellos.

Finalmente agradecer infinitamente a Dios, por darme tantas bendiciones y permitirme seguir creciendo personal y profesionalmente, y seguir alcanzando mis metas y objetivos. 


\section{RESUMEN}

Este trabajo de investigación "Perspectiva de género en las instituciones públicas y privadas y en las Políticas Públicas" busca identificar y analizar la situación de las mujeres profesionales dentro de las entidades públicas y privadas en el país y en particular en los puestos jefaturales y directivos.

Hoy en día en el Perú es evidente que existe una desigualdad de género, en nuestra sociedad, en las instituciones públicas y privadas, evidenciando una falta de Políticas Públicas, que promuevan la equidad de género. En este trabajo de investigación, se abarcarán temas de identificación de brechas de género en diferentes campos tanto en la gestión pública como en la privada, se mostrarán estudios e informes realizados por SERVIR, AEQUALES, algunos Ministerios, entre otros.

En la primera parte del presente estudio, se ha identificado la problemática de esta situación, se muestra el Informe de SERVIR "La Mujer en el Servicio Civil Peruano 2019", también sobre el objetivo de la ODS en cuanto a la Igualdad de género.

Se muestra además un resumen del Informe de resultados RANKING PAR 2019, de AEQUALES, con valiosos datos.

Finalmente en las conclusiones se enfatiza la importancia que tenemos todos y todas, de asumir los retos que nos corresponde como país y como sociedad para cerrar las brechas existentes tanto en el servicio civil, como en la sociedad en general.

Palabras clave: Mujer; perspectiva de género, servicio civil; brechas de género 


\title{
The Gender Perspective in Public Institutions and Policies
}

\begin{abstract}
This research work "Gender perspective in public and private institutions and in Public Policies" seeks to identify and analyze the situation of professional women within public and private entities in the country and in particular in the management and management positions.
\end{abstract}

Nowadays in Peru it is evident that there is a gender inequality, in our society, in public and private institutions, evidencing a lack of Public Policies that promote gender equity. In this research work, issues of identification of gender gaps in different fields in both public and private management will be covered, studies and reports by SERVIR, AEQUALES, some Ministries, among others will be shown.

In the first part of the present study, the problem of this situation has been identified, the SERVIR Report "Women in the Peruvian Civil Service 2019" is shown, also on the SDG objective regarding gender equality.

A summary of the AEQUALES RANKING PAR Results Report 2019, with valuable data, is also shown.

Finally, the conclusions emphasize the importance of all of us, of assuming the challenges that correspond to us as a country and as a society to close the existing gaps both in the civil service, and in society in general.

Keywords: Woman; gender perspective, civil service; gender gaps 


\section{TABLA DE CONTENIDOS}

1 INTRODUCCION................................................................................................

2 IDENTIFICACION DE LA PROBLEMATICA ....................................................3

\subsection{IDENTIFICACIÓN DE LAS CAUSAS DE LA PROBLEMÁTICA}

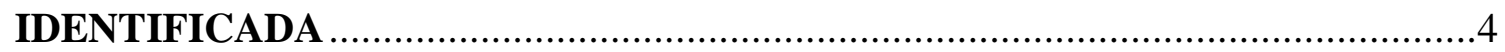

2.1.1 Menor número de mujeres que postulan a cargos directivos y/o jefaturales en relación a los hombres:

2.1.2 Preferencias de de contratación por parte de los empleadores determinadas por factores de género...

2.1.3 Cultura organizacional patriarcal (preferencia del liderazgo masculino)..8

2.2 IDENTIFICACIÓN DE LOS EFECTOS . .9

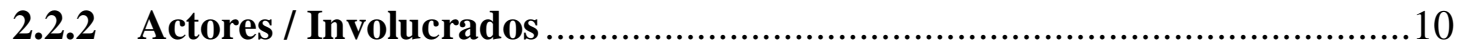

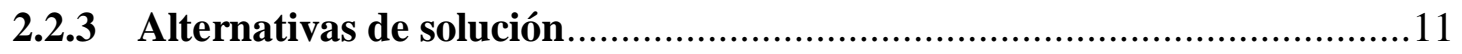

3 LA PERSPECTIVA DE GÉNERO EN LAS INSTITUCIONES Y POLITICAS

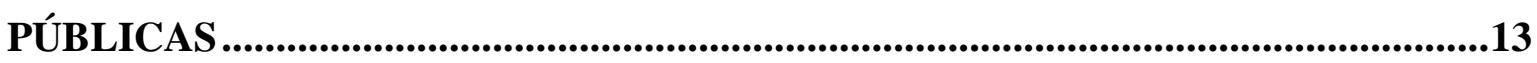

3.1 LA MUJER EN EL SERVICIO CIVIL PERUANO 2019.......................... 14

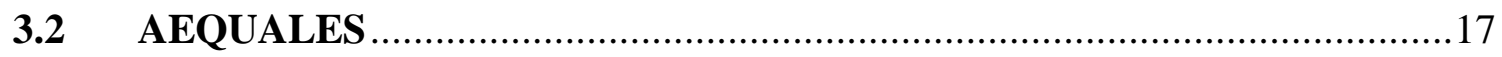

3.2.1 Informe de resultados RANKING PAR 2019 .....................................17

3.3 LA IMPORTANCIA DEL DIÁLOGO SOCIAL EN LA IGUALDAD DE GÉNERO...........21

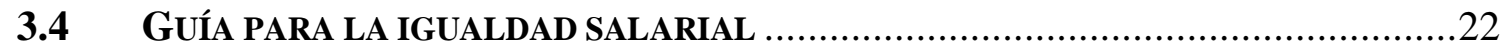

3.5 LEY QUE PROHÍBE LA DISCRIMINACIÓN REMUNERATIVA ENTRE VARONES Y MUJERES

4 LA IGUALDAD DE GÉNERO Y LOS OBJETIVOS DE DESARROLLO

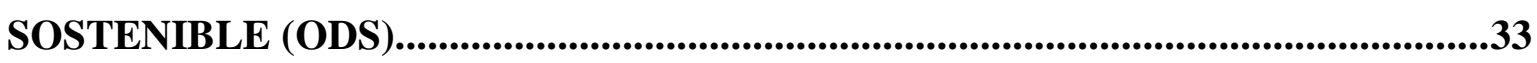

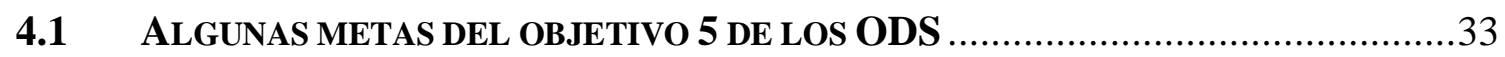

4.2 DATOS DESTACABLES DE LOS ODS, EN REFERENCIA AL TEMA DE GÉNERO: ....34

5 CONVERSANDO SOBRE LA PARTICIPACIÓN POLITICA DE LAS

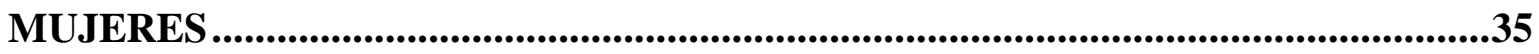

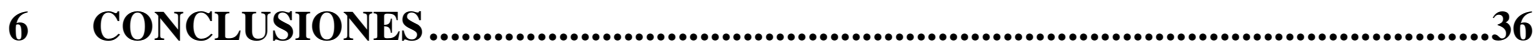




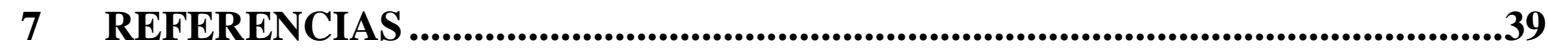

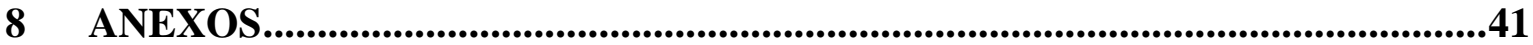




\section{ÍNDICE DE TABLAS}

Tabla 1 Cantidad de Postulantes por género ...................................................................

Tabla 2 Tiempo de trabajo destinado por semana al trabajo total de mujeres y hombres ....6

Tabla 3 Análisis - Árbol del Problema identificado .....................................................

Tabla 4 Actores identificados, interés y poder ............................................................ 10

Tabla 5 Alternativas de Solución.................................................................................. 11

Tabla 6 Porcentaje de mujeres en posiciones de alta dirección en el mundo.......................17

Tabla 7 Participación de la mujeres en las organizaciones ............................................. 19

Tabla 8 Porcentaje de participación de las mujeres en cargos ........................................19

Tabla 9 Mujeres en cargos directivos en el ámbito empresarial en América ......................42

Tabla 10 Cuota de género y otras iniciativas en el mundo..............................................43

Tabla 11 Ficha de datos del $\%$ de cargos directivos ocupados por mujeres ......................46

Tabla 12 Ficha de datos de la tasa de incremento anual de cargos directivos ocupados por

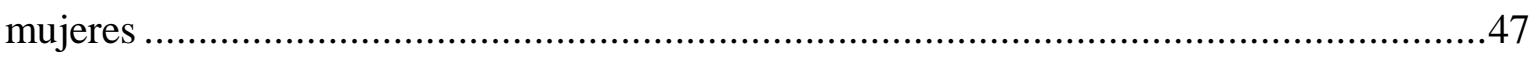

Tabla 13 Ficha de datos del porcentaje de mujeres que postulan a cargos directivos .........48 


\section{ÍNDICE DE FIGURAS}

Figura 1 La Mujer en el Servicio Civil Peruano................................................................ 16

Figura 2 Porcentaje de participación de mujeres en edad de trabajar...............................23

Figura 3 Porcentaje de jornada laboral de las mujeres....................................................24

Figura 4 Participación de las mujeres en ocupaciones menos remuneradas ......................25

Figura 5 Porcentaje de ingresos de las mujeres a nivel nacional..................................26

Figura 6 Porcentaje de ingresos de las mujeres en los medios rural y urbano ...................27

Figura 7 Porcentaje de brecha salarial en el sector público ........................................28

Figura 8 Porcentaje de brechas salariales entre hombre y mujeres ...............................29

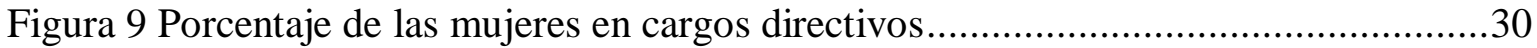

Figura 10 Procedimiento para implementar medidas de igualdad salarial ........................31

Figura 11 Buenas Prácticas a destacar en el tema de igualdad de género........................49 


\section{INTRODUCCION}

Este Trabajo de investigación tiene como objetivo analizar la perspectiva de género en las instituciones públicas y privadas y en las Políticas Públicas de nuestro país, con énfasis en el sector público; así como promover la reflexión sobre la base de la experiencia, informes realizados, reflexiones, buenas prácticas y lecciones aprendidas en otros países.

Además, busca identificar y analizar la situación de las mujeres profesionales dentro de las entidades públicas en el país y en particular en los puestos jefaturales y directivos.

Hoy en día en el Perú es evidente que existe una desigualdad de género, en nuestra sociedad, en las instituciones públicas y privadas, evidenciando una falta de Políticas Públicas, que promuevan la equidad de género.

La Autoridad del Servicio Civil - SERVIR, ha emitido este año 2019 su informe "La mujer en el servicio civil peruano 2019", sobre la presencia de la mujer en el servicio civil peruano, donde indica que casi 5 de 10 servidores públicos somos mujeres y que tanto en el sector público como en el privado formal, los hombres tienen una mayor participación en el mercado laboral, la presencia de la mujer en el sector público es mayor, dado que, prácticamente, 5 de cada 10 servidores son mujeres, mientras que 3 de cada 10 personas que trabajan en el sector privado formal lo son.

En este trabajo de investigación, se abarcarán temas de evaluación de la brecha de género en la gestión pública, sus instrumentos y lecciones aprendidas; algunas buenas prácticas para la implementación de una política de equidad de género en otros países, información sobre el tema tan lamentable de violencia de Género, entre otros.

Analizaremos la necesidad imperante de empoderar a la mujer, e incorporarla en puestos directivos, en cargos políticos, en la economía del país, etc.

En la primera parte del presente estudio, se ha identificado los principales obstáculos y/o barreras de las mujeres para acceder a puestos directivos. Considerando la diferente bibliografía revisada, se ha definido como problema central el "Reducido número de mujeres que ocupan cargos directivos en el sector público en Lima”. 
Asimismo, se han identificado las principales causas que explicarían el problema central, éstas están relacionadas al menor número de mujeres que postulan a puestos directivos y a las preferencias de contratación por parte de los empleadores.

También se presentan propuestas de alternativas de solución, las cuales podrían ser usadas como insumo para diseñar Políticas Públicas que permitan reducir la brecha identificada, identificada en el presente trabajo de investigación.

Finalmente en las conclusiones se enfatiza la importancia que tenemos todos y todas, de asumir los retos que nos corresponde como país y como sociedad para cerrar las brechas existentes tanto en el servicio civil, como en la sociedad en general. 


\section{IDENTIFICACION DE LA PROBLEMATICA}

En el mundo de hoy, hay un mayor debate entre los diferentes líderes empresariales y de los gobiernos sobre la participación de las mujeres en las organizaciones, y su contribución en los beneficios sociales, económicos y financieros, tanto en el sector privado como en el sector público. Asimismo, cada vez existe un mayor interés en incorporar en las agendas temas que contengan enfoques de igualdad de género.

Se ha encontrado diversa literatura que hace referencia a la situación de la mujer en el ámbito laboral, de ella se desprende que en muchos países la presencia de la mujer es menor al del hombre, sobre todo en el segmento donde se requieren competencias de liderazgo.

Las estadísticas de la Organización Internacional del Trabajo ${ }^{1}$ revelan que las mujeres representan cerca del $40 \%$ de la mano de obra en el mundo. Por otro lado, la participación global en los puestos directivos en las diferentes empresas no supera el $20 \%$, llegando incluso al $2 \%$ o $3 \%$ en las grandes empresas.

En el Perú, solo el 61\% de las mujeres en edad de trabajar se encuentran laborando, frente a una cifra que alcanza el $79 \%$ en el caso de los hombres, es decir, la tasa de brecha de género alcanza el $18 \%$.

Informe que presenta la Autoridad Nacional del Servicio Civil - SERVIR "La Mujer en el Servicio Civil Peruano 2019" menciona que casi 5 de cada 10 personas al servicio del Estado son mujeres, frente a 3 de cada 10 en el sector privado formal, siendo 16 los departamentos que han alcanzado la paridad de género, además analiza la trayectoria de un conjunto de indicadores que reflejan el papel de la mujer en el servicio civil peruano durante el período 2004 - 2017, en el marco de las políticas de Estado que buscan promover la igualdad de oportunidades entre hombres y mujeres.

Para acortar las diferentes brechas de equidad de género, que se analizarán en el presente trabajo de investigación, tanto en el sector público como privado es necesario políticas públicas que permitan establecer acciones en los tres niveles de gobierno, sectores y organizaciones civiles.

\footnotetext{
${ }^{1}$ (Organización Internacional del Trabajo (OIT, 2009). Panorama Laboral 2009: América Latina y el Caribe. Lima: Autor)
} 
Para tal fin, en el presente trabajo de investigación se ha identificado como uno de los problemas principales, el reducido número de mujeres que ocupan cargos directivos en las organizaciones del Perú.

\subsection{IDENTIFICACIÓN DE LAS CAUSAS DE LA PROBLEMÁTICA IDENTIFICADA}

Como parte de la investigación del problema, se han identificado causas de primer y de segundo nivel.

\subsubsection{Menor número de mujeres que postulan a cargos directivos y/o jefaturales en relación a los hombres:}

En relación a la primera causa, según información proporcionada por la Autoridad Nacional del Servicio Civil - SERVIR, en los procesos de selección al Cuerpo de Gerentes Públicos (CGP) realizados entre los años 2012 al 2015, hubo 7,907 (28\%) postulantes mujeres al CGP; mientras que 20,226 (72\%) de los postulantes han sido hombres (GDGP, 2016).

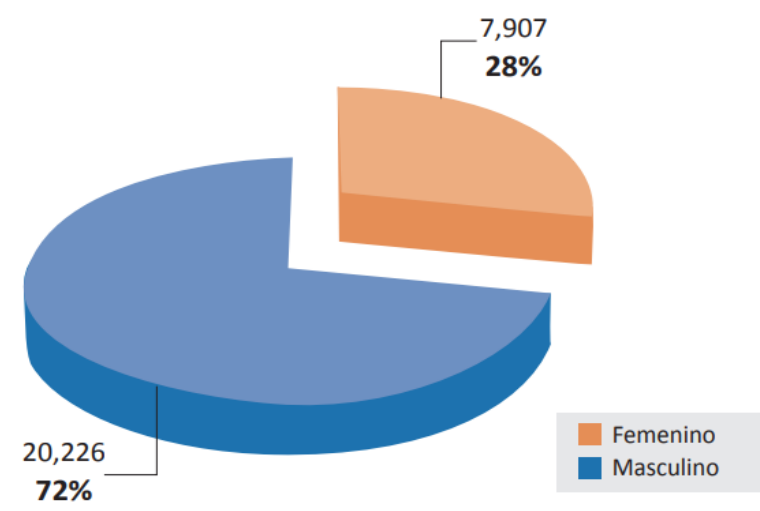

Fuente: Gerencia de Desarrollo de la Gerencia Pública, SERVIR, 2016 
Asimismo, a partir de la estadística histórica revisada sobre los procesos de selección del Cuerpo de Gerentes Públicos (CGP), se halló que, del total de postulantes, se han incorporado al CGP 770 Gerentes Públicos; de los cuales, 204 del total son mujeres y 466 son hombres.

Los datos presentados ponen en evidencia que las mujeres postulan en menor nivel que los hombres a cargos directivos y/o jefaturales. A partir de esto, se desarrollarán dos causas de segundo nivel.

\section{a. Síndrome de doble carga: Desequilibrio entre la vida personal y profesional}

Como primera causa de segundo nivel, se puede identificar el "síndrome de doble carga" en las mujeres, cuando se encuentran en el proceso de buscar un balance entre su desarrollo profesional y las responsabilidades domésticas asumidas; debido a que muchas mujeres combinan sus responsabilidades laborales con una gran parte de las responsabilidades familiares (McKinsey \& Company, 2013).

Por un lado, es de resaltar que el "síndrome de doble carga" fue identificado como el principal obstáculo para incrementar la diversidad de género en cargos gerenciales por $44 \%$ de los ejecutivos encuestados para el estudio realizado por el Banco Interamericano de Desarrollo (BID) en 345 empresas de América Latina y el Caribe (BID, 2015). Asimismo, según el estudio "Women Matter: A Latin American Perspective", para el 50\% de las encuestadas, la principal barrera para el crecimiento profesional de la mujer en Latinoamérica es el "síndrome de la doble carga" y en segundo lugar, el $46 \%$ de encuestadas identificó que el modelo presencial que exige estar disponible "en todo momento y en todo lugar" a quienes ocupan altos cargos genera que el síndrome de la doble carga sea aún más pesado (McKinsey \& Company, 2013).

Por otro lado, es muy importante tener en cuenta que el tiempo es un recurso limitado en la vida de cada persona, y que existe una relación inversamente proporcional entre el tiempo dedicado al trabajo (remunerado o no remunerado) con el tiempo dedicado a otras actividades. Según el Instituto Nacional de Estadística e Informática, en los últimos años ha habido un incremento de mujeres peruanas incorporadas al mercado laboral, lo que incrementa las horas totales destinadas al trabajo en general. Es así que, a partir de la Encuesta Nacional de Uso del Tiempo, se evidencia que las mujeres en el Perú trabajan 75 horas, 54 minutos en promedio; mientras que los hombres trabajan 66 horas 39 minutos; lo que genera una brecha de género 9 horas 15 minutos, tal como se puede observar en el siguiente gráfico (INEI, 2016). 


\section{Perú: Tiempo de trabajo destinado por semana al trabajo total por mujeres y hombres. 2010 (Horas/minutos)}

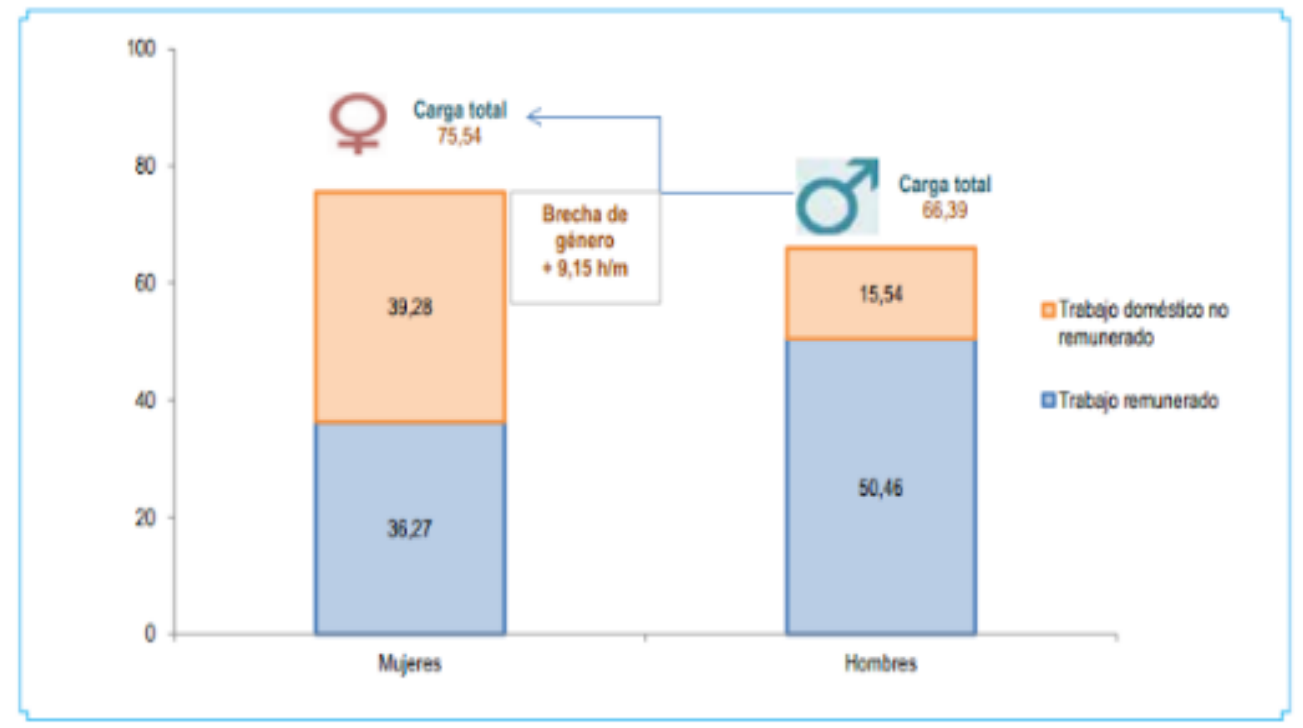

Fuente: Instituto Nacional de Estadística e Informática-Encuesta Nacional de Uso del Tiempo, 2010

Esta brecha de género se puede explicar a partir del hecho de que las mujeres peruanas aparte de sus responsabilidades en labores remuneradas, estas dedican un tiempo significativo a labores no remuneradas como el cuidado de otros, la mantención de la casa y las actividades asociadas a la familia, en contraste, los hombres le dedican la mayor parte de su tiempo al trabajo remunerado y un tiempo reducido al trabajo no remunerado.

\section{b. Poca experiencia profesional de mujeres en cargos directivos y/o jefaturales.}

Como segunda causa de segundo nivel, se ha identificado que el reducido número de mujeres en cargos directivos y/o jefaturales se debe a que ellas no cumplirían con los requisitos mínimos de experiencia laboral solicitada para este tipo de puestos.

Dado el reciente incremento de mujeres peruanas incorporadas al mercado laboral y dado que alcanzar los niveles más altos a nivel profesional, generalmente, requiere de una amplia experiencia laboral, se concluye que habría menos mujeres que hombres que han alcanzado altos niveles de experiencia para poder acceder a puestos directivos y/o jefaturales.

$\mathrm{O}$, presentado de otra manera, la edad media de las trabajadoras es inferior a la de los trabajadores y por tanto hay menos mujeres en los intervalos de edad en los que habitualmente se alcanza altos niveles de experiencia profesional (Albert, Escot, Fernández, Mateos, 2008). 
Además de tener menor experiencia profesional en promedio, las mujeres deben tener en cuenta que algunas de ellas han efectuado interrupciones en su vida profesional relacionadas con la maternidad y el cuidado de los hijos u otros familiares. Por otra parte, también en este ámbito se pueden dar situaciones de discriminación por parte del empleador, ya que algunas organizaciones, anticipando que en promedio se van a producir más abandonos de puestos de trabajo por parte de las mujeres que por parte de los hombres, pueden decidir invertir más en la formación de los segundos (Albert et al., 2008).

Una de las tesis que se dan a conocer en el documento de "Brecha género en el acceso a puestos directivos: características y principales obstáculos en el ámbito nacional e internacional" (SERVIR, 2016) es que las mujeres tendrían menor acceso a puestos directivos y/o jefaturales, debido a que generalmente la asignación que se realiza a puestos directivos es por confianza, y los tomadores de decisiones tienen mayor preferencia por el liderazgo masculino.

Del análisis de información de procesos de selección del cuerpo de Gerentes Públicos que la GDGP- SERVIR (2012 al 2015), se identifica que en algunos puesto ofertados dentro de la convocatoria se solicita que los postulantes tengan disponibilidad de trabajar en un departamento distinto al lugar de residencia, lo que según la información recabada del área de Asignaciones, encargada de la presentación de la terna finalista a la entidad solicitante, muchas veces está requerimiento inhibe la postulación de las mujeres debido a la responsabilidad que asumen respecto a la familia. Esto demuestra que las mujeres en su mayoría dan mayor prioridad a su vida personal sobre su formación profesional, ocasionando la interrupción o un desarrollo más lento de su carrera profesional, lo que genera menor experiencia, laborar medio tiempo o trabajos temporales, y reducción de sus ingresos.

\subsubsection{Preferencias de de contratación por parte de los empleadores determinadas por factores de género.}

Como segunda causa principal del problema estudiado encontramos que en relación a la demanda de empleadores, varios documentos señalan que los factores de género están presentes en las preferencias de contratación. En Latinoamérica el 28\% de la población ${ }^{2}$ cree que en igualdad de condiciones (aptitudes) las mujeres tienen menores probabilidades de contratación o ascenso frente a un hombre. Asimismo, un estudio experimental realizado en Lima Metropolitana ${ }^{3}$ mostró entre sus hallazgos la preferencia de los postulantes hombres frente a las mujeres, los postulantes hombres reciben en promedio 34\% más llamadas por parte de los empleadores que las mujeres.

Estas preferencias de contratación, se acentúa en el caso de puestos directivos o jefaturales, en donde se requieren competencias de liderazgo.

\footnotetext{
2 Según la encuesta de opinión pública Latinobarómetro, elaborada por The Economist.

${ }^{3}$ Galarza y Yamada (2012)
} 
El estudio "Women in Senior Management. Setting the stage for growth" concluye que entre las barreras para el Desarrollo de las Mujeres en Puestos Directivos en Latinoamérica se tienen los siguientes:

- Factores culturales relacionados con la consideración que "el hombre es el jefe"

- El hecho que las posiciones de alta dirección requieren horarios exigentes y frecuentes viajes, lo cual únicamente puede ser compensado con un fuerte soporte en sus hogares, en el cuidado de hijos y responsabilidades domésticas

- Las expectativas sobre las mujeres son muy altas, debido a que son juzgadas no solamente por su desempeño laboral, sino también por "como se viste, como se ven, y cómo funciona su balance vida trabajo".

Estos factores presentan componentes culturales tanto en la población como en las organizaciones.

\subsubsection{Cultura organizacional patriarcal (preferencia del liderazgo masculino)}

Las preferencias en la contratación de hombres en cargos directivos están directamente relacionadas a las preferencias por un liderazgo masculino frente al liderazgo femenino, lo que llamamos una Cultura organizacional patriarcal.

Según el estudio de Género y Políticas de Recursos Humanos: Calidad del Empleo de las Mujeres ${ }^{5}$ realizado por Centrum, se identifica resistencias al liderazgo femenino, entre las principales características se mencionan $^{6}$ :

- Las características esperadas de un líder son más asociadas con los hombres que con las mujeres. Existe la percepción de que las características asociadas a las mujeres son más orientadas hacia lo comunal (amigables, sensitivas, amables, caritativas, compasivas); mientras que la percepción de las características de los hombres, suele ser más orientado hacia el agente (asertivos, ambiciosos, agresivos, y seguros de sí mismos), siendo estas últimas características las que más se asocian al liderazgo.

- Usualmente las personas son más resistentes a la influencia de una mujer que a la de un hombre.

- Prejuicios. Éstos están asociados, por un lado, a que se cree que el liderazgo de la mujer rompe con el rol tradicional del liderazgo masculino, por otro lado, a las brechas salariales entre hombre y mujeres.

\footnotetext{
4 (Grant Thornton IBR, 2013, p. 11)

${ }^{5}$ Centrum - Beatrice Avolio Alecchi

6 (Eagly \& Carli, 2007)
} 


\subsection{IDENTIFICACIÓN DE LOS EFECTOS}

A partir de la elaboración de un Árbol de problemas se considera que el reducido número de mujeres que ocupan cargos directivos en el sector público en Lima tiene dos efectos principales.

Por un lado se considera que existiría una poca visibilización del rol de la mujer en la gestión pública, lo que a su vez decantaría en la poca valoración de los aportes de la mujer a la gestión del sector público.

Por otro lado, se identifica que existe una poca elaboración e implementación de (o ausencia) políticas relacionadas a la promoción de mujeres en cargos directivos y/o jefaturales; esto a su vez genera que las mujeres tengan menores posibilidades, con respecto a los hombres, para ocupar puestos directivos y/o jefaturales y que además la tasa de ocupación en puestos con menores salarios, sea alta.

Tabla

Análisis - Árbol del Problema identificado

\section{Árbol del Problema}

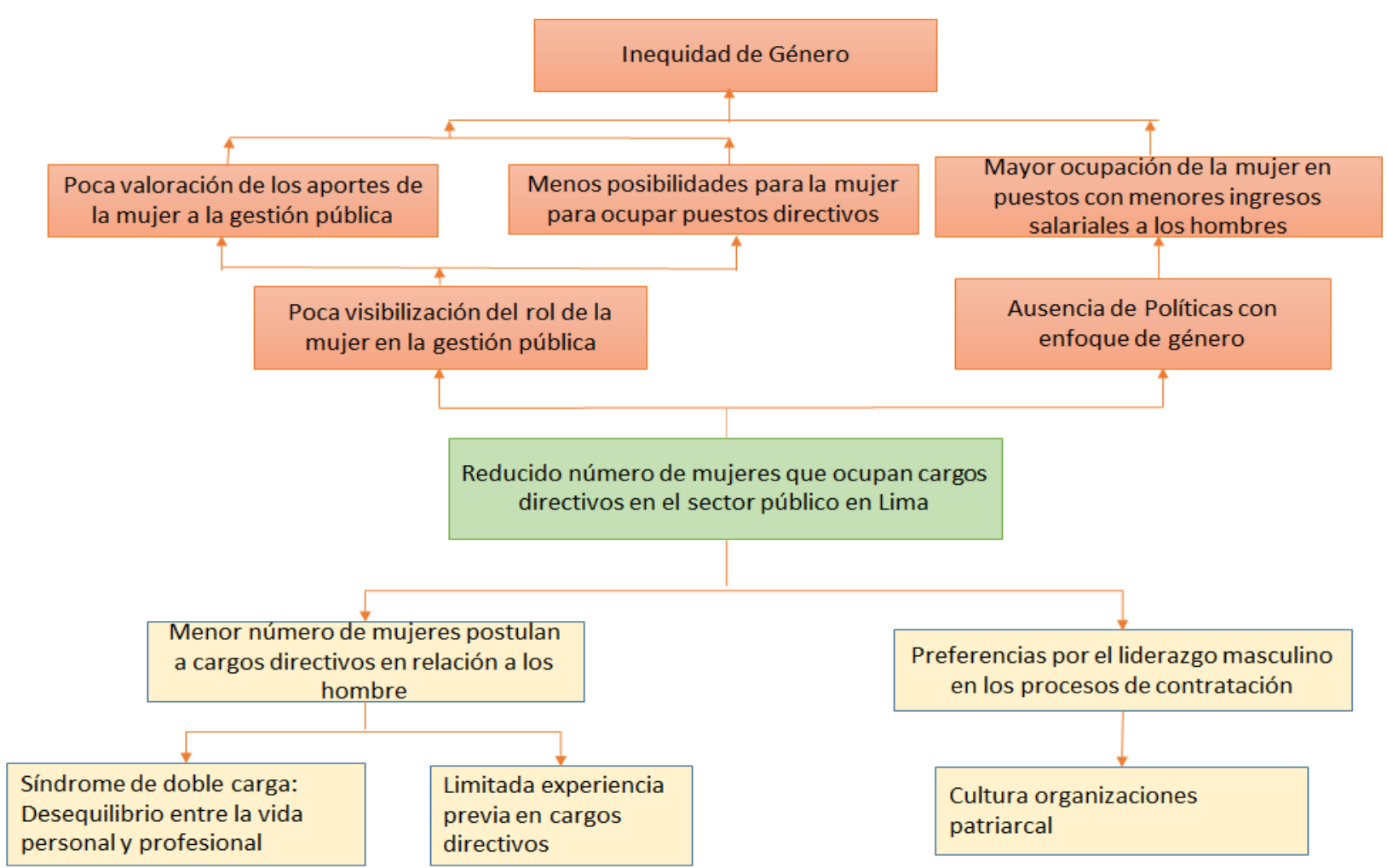




\subsubsection{Actores / Involucrados}

Los Actores / Involucrados identificados en esta investigación, así como sus intereses y su poder o potencial en interferir en el problema son;

Actores identificados, interés y poder

\begin{tabular}{|c|c|c|}
\hline $\begin{array}{l}\text { Actores } \\
\text { Involucrados }\end{array}$ & Intereses & Poder / Potencial \\
\hline $\begin{array}{l}\text { Escuelas de post } \\
\text { grado }\end{array}$ & $\begin{array}{l}\text { Falta de interés en el problema } \\
\text { público }\end{array}$ & $\begin{array}{l}\text { Medio, generar } \\
\text { información para } \\
\text { contribuir a definir el } \\
\text { problema público. }\end{array}$ \\
\hline $\begin{array}{l}\text { PCM - Secretaría de } \\
\text { Gestión Pública }\end{array}$ & $\begin{array}{l}\text { Modernización de la gestión } \\
\text { pública con enfoque de género }\end{array}$ & $\begin{array}{l}\text { Alto, Formular Políticas } \\
\text { Públicas que permitan } \\
\text { fortalecer el rol de las } \\
\text { mujeres. }\end{array}$ \\
\hline El Congreso & $\begin{array}{l}\text { Aprobar normas que garanticen } \\
\text { la igualdad de oportunidades } \\
\text { entre hombres y mujeres }\end{array}$ & $\begin{array}{l}\text { Alto, Aprobar leyes en } \\
\text { favor de la equidad de } \\
\text { género. }\end{array}$ \\
\hline $\begin{array}{l}\text { Autoridad Nacional } \\
\text { del Servicio Civil - } \\
\text { SERVIR }\end{array}$ & $\begin{array}{l}\text { Incrementar la participación de } \\
\text { las mujeres en cargos directivos }\end{array}$ & $\begin{array}{l}\text { Medio - alto, identificar } \\
\text { brechas de género que } \\
\text { sirvan de insumo para } \\
\text { generar políticas públicas. }\end{array}$ \\
\hline $\begin{array}{l}\text { ONGs - Manuela } \\
\text { Ramos / Flora } \\
\text { Tristán, entre otras y } \\
\text { organizaciones de }\end{array}$ & $\begin{array}{l}\text { Combatir las causas estructurales } \\
\text { que restringe la ciudadanía de las } \\
\text { mujeres y su ejercicio }\end{array}$ & $\begin{array}{l}\text { Medio - bajo, generar } \\
\text { información y poder de } \\
\text { convocatoria para poner } \\
\text { temas en la agenda }\end{array}$ \\
\hline
\end{tabular}




\begin{tabular}{|c|c|c|}
\hline mujeres. & & política. \\
\hline $\begin{array}{l}\text { Ministerio de la } \\
\text { Mujer }\end{array}$ & $\begin{array}{l}\text { Fortalecer las instituciones } \\
\text { públicas en la gestión de } \\
\text { políticas de igualdad de género. } \\
\text { Garantizar y proteger los } \\
\text { derechos de las mujeres }\end{array}$ & $\begin{array}{l}\text { Alto, emitir informes, } \\
\text { estudios, normativas con } \\
\text { enfoque de género, que } \\
\text { sirvan de insumo para } \\
\text { generar políticas públicas. }\end{array}$ \\
\hline
\end{tabular}

\subsubsection{Alternativas de solución}

Según lo investigado, se han identificado las siguientes alternativas de solución, de acuerdo a los actores e involucrados identificados y a los objetivos planteados;

Alternativas de Solución

\begin{tabular}{|c|c|c|c|}
\hline \multirow{2}{*}{$\begin{array}{c}\text { Actores / } \\
\text { Involucrados }\end{array}$} & \multicolumn{3}{|c|}{ Alternativas de Solución } \\
\hline & $\begin{array}{lrr}\text { Objetivo } & \text { 1: } \\
\text { Incrementar } & \text { los } \\
\text { niveles de } & \text { equidad } \\
\text { entre la } & \text { vida } \\
\text { personal } & \text { y } \\
\text { profesional de } & \text { la } \\
\text { mujer } & & \end{array}$ & $\begin{array}{lr}\text { Objetivo } & 2: \\
\text { Incrementar } & \text { el } \\
\text { número de } & \text { mujeres } \\
\text { con } & \text { experiencia } \\
\text { necesaria } & \text { para } \\
\text { postular a } & \text { puestos } \\
\text { directivos } & \end{array}$ & $\begin{array}{l}\text { Objetivo 3: } \\
\text { Fortalecer la } \\
\text { cultura } \\
\text { organizacional con } \\
\text { enfoque de género }\end{array}$ \\
\hline $\begin{array}{l}\text { Escuelas de } \\
\text { post grado }\end{array}$ & \multicolumn{3}{|c|}{$\begin{array}{l}\text { Incluir en sus mallas curriculares, objetivos propuestos, enfoque de } \\
\text { género y el plan nacional de igualdad del MIMP. } \\
\text { Dictado de programas promoviendo los temas de enfoque de género. }\end{array}$} \\
\hline $\begin{array}{l}\text { PCM } \\
\text { Secretaría de } \\
\text { Gestión } \\
\text { Pública }\end{array}$ & & $\begin{array}{l}\text { Formular políticas de } \\
\text { estado con enfoque de } \\
\text { género. }\end{array}$ & $\begin{array}{l}\text { Formular políticas de } \\
\text { estado con enfoque } \\
\text { de género. }\end{array}$ \\
\hline El Congreso & \multicolumn{3}{|c|}{ Incluir en los planes de la comisión de la Mujer, la fiscalización del } \\
\hline
\end{tabular}




\begin{tabular}{|l|l|l|l|}
\hline & \multicolumn{2}{|l|}{$\begin{array}{l}\text { plan nacional de igualdad de género del MIMP. } \\
\text { Aprobar leyes con enfoque de género. }\end{array}$} \\
\hline Servir & $\begin{array}{l}\text { Proponer normas que } \\
\text { regulen los horarios } \\
\text { de trabajo para } \\
\text { Directivos. }\end{array}$ & $\begin{array}{l}\text { Promover encargaturas } \\
\text { con enfoque de género } \\
\text { para cargos directivos. }\end{array}$ & $\begin{array}{l}\text { Realizar } \\
\text { investigaciones de } \\
\text { temas de género. }\end{array}$ \\
\hline $\begin{array}{l}\text { ONG } \\
\text { Manuela } \\
\text { Ramos / Flora } \\
\text { Tristán } \\
\begin{array}{l}\text { Asociaciones } \\
\text { de mujeres }\end{array}\end{array}$ & $\begin{array}{l}\text { Realizar programas } \\
\text { de sensibilización en } \\
\text { línea con el objetivo. }\end{array}$ & $\begin{array}{l}\text { Realizar } \\
\text { investigaciones de } \\
\text { temas de género. }\end{array}$ \\
\hline $\begin{array}{l}\text { Ministerio de } \\
\text { la Mujer y } \\
\text { Poblaciones } \\
\text { Vulnerables }\end{array}$ & $\begin{array}{l}\text { Incluir en su Plan Nacional de Igualdad de } \\
\text { objetivos propuestos. }\end{array}$ & Género, enfoques y \\
\hline
\end{tabular}

\section{Alternativas de solución al problema identificado:}

$\checkmark$ Las escuelas de post grado incluyan en sus mallas curriculares los objetivos propuestos, y el dictado de programas promoviendo los temas de enfoque de género y el plan nacional de igualdad de género del MIMP.

$\checkmark$ La PCM a través de su Secretaría de Gestión Pública, formule políticas de estado con enfoque de género.

$\checkmark$ El MIMP incluya en los planes de la comisión de la Mujer, la fiscalización del plan nacional de igualdad de género.

$\checkmark$ Aprobación de leyes con enfoque de género por el Congreso.

$\checkmark$ Servir debe continuar emitiendo propuestas de normativas que regulen horarios de trabajo para Directivos, y otros beneficios o concesiones, a fin de motivar la igualdad de condiciones en las jornadas laborales.

$\checkmark$ Servir debe promover que en las entidades del estado se den las encargaturas con enfoque de género para cargos directivos, a fin de promover la experiencia en cargos directivos de las mujeres.

$\checkmark$ Servir debe continuar realizando investigaciones de temas de enfoque de género.

$\checkmark$ Las ONG como Manuela Ramos, Flora Tristán y/o Asociaciones de mujeres realicen programas, talleres, conferencias, foros, etc, de sensibilización, fortalecimiento y empoderamiento hacia las mujeres.

$\checkmark$ El Ministerio de la Mujer y de Poblaciones Vulnerables, deben incluir en el Plan Nacional de Igualdad de Género, los objetivos propuestos en nuestro árbol de 
objetivos con el fin de Incrementar el número de mujeres con experiencia necesaria para postular a puestos directivos e incrementar los niveles de equidad entre la vida personal y profesional de la mujer.

$\checkmark$ Servir debe continuar emitiendo propuestas de normativas que regulen horarios de trabajo para Directivos, y otros beneficios o concesiones, a fin de motivar la igualdad de condiciones en las jornadas laborales. En este caso nos referimos, a que la Autoridad Nacional del Servicio Civil - SERVIR, continúe realizando estudios que reflejan el papel de la mujer en el servicio civil peruano, cuáles son sus condiciones laborales, sus dificultades, objetivos y expectativas en sus entidades. El propósito de esta alternativa de solución es que en las entidades exista un clima laboral basado en el respeto y la no discriminación, asegurando así prácticas preventivas y que además promuevan sanciones al hostigamiento de todo tipo.

$\checkmark$ Las ONG como Manuela Ramos, Flora Tristán y/o Asociaciones de mujeres realicen programas, talleres, conferencias, foros, etc, de sensibilización, fortalecimiento y empoderamiento hacia las mujeres. Son movimientos y/o asociaciones comprometidas con el logro de la igualdad de género, que trabajan por los derechos de las mujeres, los derechos humanos y el respeto por la institucionalidad democrática.

$\checkmark$ La propuesta que al realizar este tipo de eventos con convocatoria de mujeres se toquen temas con un enfoque socializador que contribuya a revalorizar su tarea y contribuya al establecimiento de una red de actuaciones con perspectiva de género dentro de la dinámica de sus actividades.

\section{LA PERSPECTIVA DE GÉNERO EN LAS INSTITUCIONES Y POLITICAS PÚBLICAS}

La igualdad de género es un asunto que incumbe a todos porque crea economías más prósperas y sociedades más justas. En la región ya se nota el impacto de la creciente participación femenina en el mercado laboral, un factor que ayudó a reducir la pobreza significativamente durante la década pasada, sin embargo queremos analizar y reflexionar sobre las alternativas y herramientas que permitan a las empresas establecer estrategias de igualdad de género.

Las mujeres hoy aportan entre $30 \%$ y $60 \%$ de los ingresos familiares en nuestros países. Debido al mayor acceso a la educación, casi $23 \%$ de las mujeres que trabajan han pasado por la universidad, frente a $61 \%$ de los hombres, esto es clave para el futuro, porque la acumulación de destrezas es indispensable para aumentar el crecimiento económico.

En el año 2017 el Congreso aprobó el proyecto de Ley presentado por la Congresista y Mercedes Araoz sobre igualdad salarial entre hombres y mujeres, lo cual incluyó en la agenda el 
tema de género, la igualdad de oportunidades y del reconocimiento de los derechos de las mujeres en el país. Esta ley prohíbe la discriminación salarial entre hombres y mujeres, además garantiza un trato digno, un clima laboral basado en el respeto y la no discriminación, asegura prácticas preventivas y promueve la sanción al hostigamiento sexual.

En el discurso del Premier del 04 de abril del 2019, para solicitar el voto de confianza al Congreso, mencionó “... Hoy anunciamos con satisfacción la publicación de la Política Nacional de Igualdad de Género que promueve la igualdad y no discriminación entre hombres y mujeres, así como garantizar la protección de la niñez, la adolescencia y las mujeres frente a todo tipo de violencia...", se evidencia entonces la importancia y prioridad del gobierno en los temas de género.

\subsection{LA MUJER EN EL SERVICIO CIVIL PERUANO 2019}

La Autoridad Nacional del Servicio Civil - SERVIR, publica en el año 2019 el Informe "La Mujer en el Servicio Civil Peruano 2019", mencionando que en el servicio civil peruano, casi 5 de cada 10 personas al servicio del Estado son mujeres, frente a 3 de cada 10 en el sector privado formal, siendo 16 los departamentos que han alcanzado la paridad de género, además analiza la trayectoria de un conjunto de indicadores que reflejan el papel de la mujer en el servicio civil peruano durante el período 2004 - 2017, en el marco de las políticas de Estado que buscan promover la igualdad de oportunidades entre hombres y mujeres.

En este informe concluye que aún existen diferencias en cuanto al acceso y características de trabajo para hombres y mujeres en el servicio civil peruano. Sin embargo, en el período 2004 - 2017, se ha incrementado en casi 4 puntos porcentuales la proporción de servidoras públicas, siendo que entre los años 2016 y 2017 dicha proporción no varió. También menciona que el 24\% de las mujeres que trabajan en el sector público son jefas de hogar versus $19 \%$ en el sector privado formal, incidencia que ha mostrado una tendencia significativamente creciente, en el primer caso, en los últimos trece años, mientras que en el sector privado formal creció en 6 puntos porcentuales. 
Importante cuando resaltan que las funciones que realizan las mujeres en el sector público no son iguales que las que realizan los hombres. La participación de la mujer continúa siendo mayoritaria en las carreras especiales (54\%), por la fuerte presencia de enfermeras en el sector Salud y de profesoras de educación inicial y primaria en el sector Educación, situación que se ha mantenido prácticamente estable en los últimos nueve años, y que en el grupo de funcionarios y directivos, de cada 10 personas que trabajan en el sector público, 3 son mujeres, registrándose cierta tendencia decreciente desde el año 2011 que parece haberse revertido en los años 2016 y 2017.

En cuanto a la edad, mencionan que existe una mayor proporción de servidoras mujeres en el rango de 30 a 44 años (41\%), aunque su participación ha continuado reduciéndose en el período 2004 - 2016, en favor de aquellas en el rango de 45 a 64 años $(37 \%)$, como en el caso de los servidores varones.

Una conclusión importante que también mencionan es que en el período 2004 - 2017, la proporción de servidoras civiles en el grupo etario de hasta 29 años decreció de $22 \%$ a $20 \%$, lo cual podría ser un indicio de que el sector público se habría vuelto menos atractivo para las mujeres jóvenes (en relación con los ingresos y beneficios percibidos en el sector privado, por ejemplo) o que se podría haber generado algún tipo de restricción para su ingreso (como una menor demanda en sectores donde históricamente ha habido mayor presencia de hombres), considerando que en el caso de los hombres jóvenes no se ha presentado dicho patrón, lo cual deberá ser analizado con mayor detalle en próximas investigaciones.

En el siguiente gráfico se muestra una Infografía de la Mujer en el Servicio Civil Peruano 2019 


\section{La Mujer en el Servicio Civil Peruano 2019}

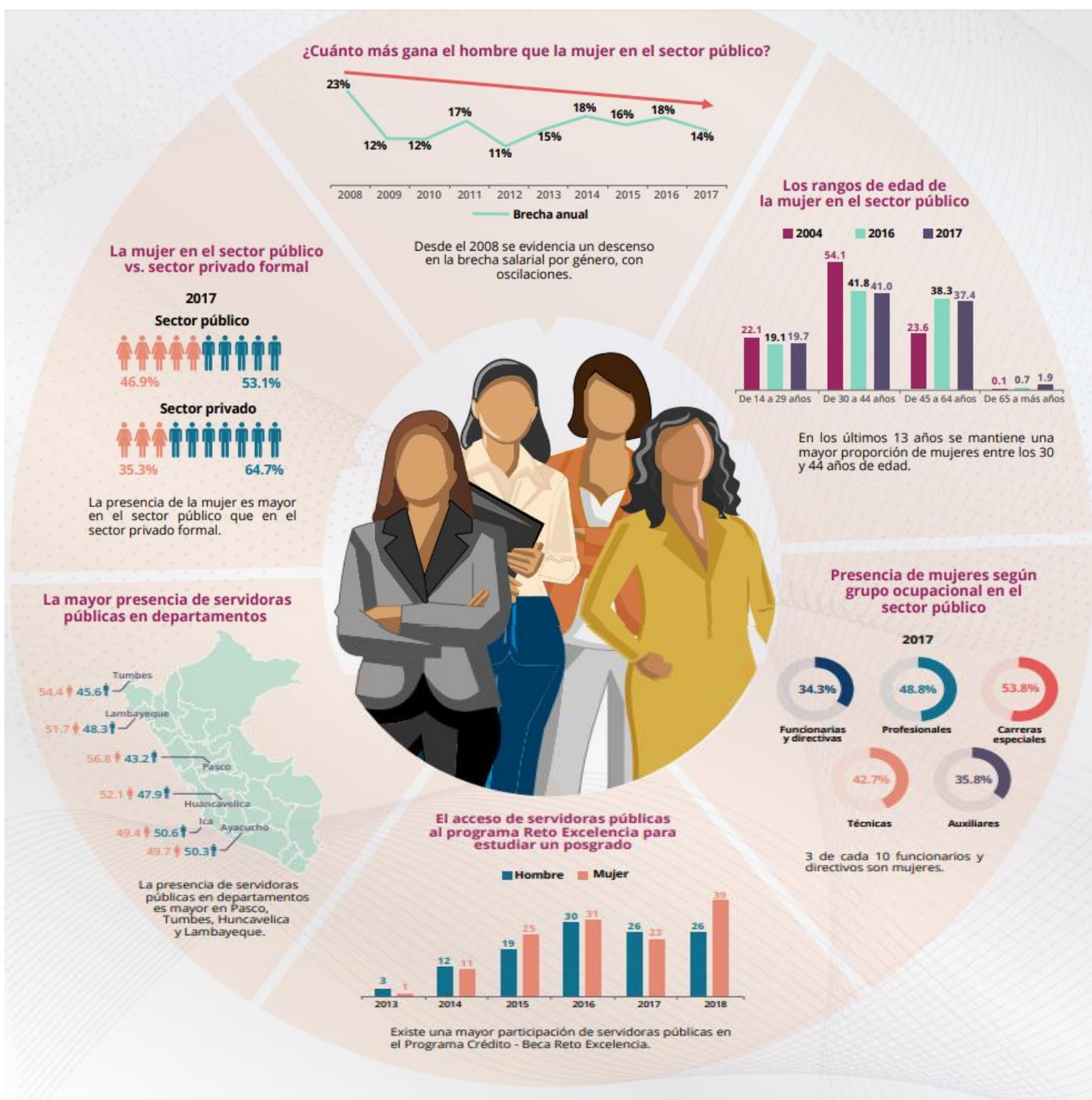

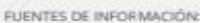

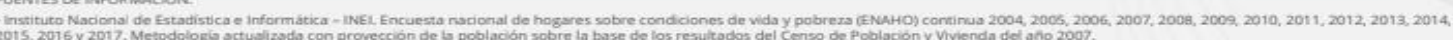
- Ministerio de Trabsoy y Promoción del Empleo - MTPE, Planill electrónica 2013 2014, 2015, 2016, 2017 y 2013

- hegistro Nacional de Muricipaldades - RENaMU 2005, 2006, 2007, 2008, 2009, 2010, 2011, 2012, 2013, 2014, 2015, 2016, 2017 y 2018.

iNFOGRAFiA: La mujer en el servikio chil peruano 2019

Pie Francisco de Zela 150, piso 10 - Jesús Maria, 15072 - Perri

Figura 1 La Mujer en el Servicio Civil Peruano 


\subsection{AEQUALES}

Aequales es una organización que promueve el empoderamiento laboral de las mujeres a través de consultoría especializada en procesos, cultura y políticas organizacionales con un enfoque de género. Trabaja para reducir las brechas de género y así generar beneficios para las empresas.

En el mes de Julio del presente año, Aequales y la Cámara Oficial de Comercio de España en el Perú dieron a conocer los resultados de su Ranking Par de Equidad de Género 2019, que evalúa y distingue el desempeño de las organizaciones en esta materia.

\subsubsection{Informe de resultados RANKING PAR 2019}

Lo más resaltante del Informe, indica que según el Global Gender Gap Report del Foro Económico Mundial (2018), aún hay una brecha de género global promedio de 32\% que se estima va a tomar 108 años en cerrarse. Específicamente, la brecha correspondiente a oportunidades y participación económica es la segunda más amplia (41.9\%) y se considera la más difícil de cerrar ya que la estimación del tiempo que va a tomar hacerlo es casi el doble que la brecha general (202 años).

Porcentaje de mujeres en posiciones de alta dirección en el mundo

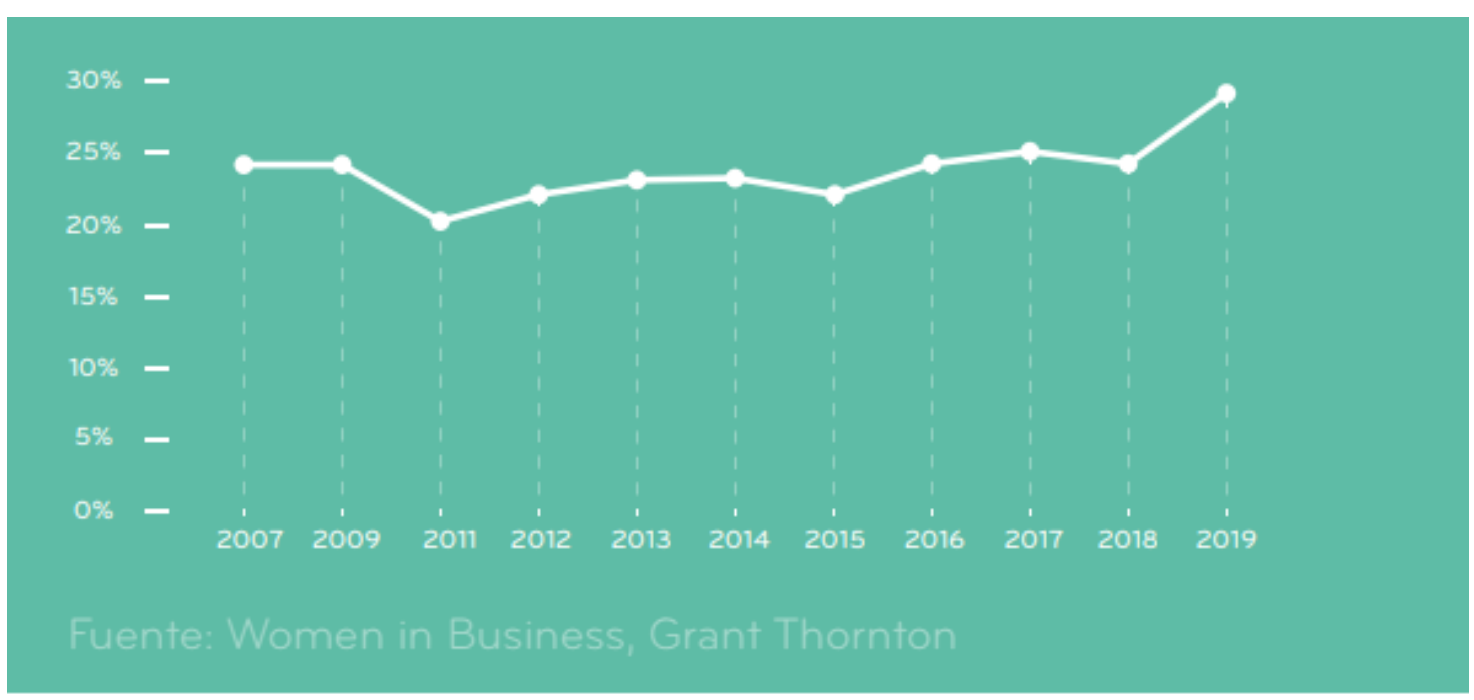

En vista de esta problemática, Aequales al lado de la Cámara Oficial de Comercio de España en el Perú realiza todos los años el Ranking PAR de equidad de género en las organizaciones. El Ranking es una herramienta gratuita que permite generar líneas base en 
términos de equidad de género, mediante una medición de las organizaciones a través de un cuestionario virtual diseñado especialmente por Aequales. Esta medición evalúa el desempeño de las organizaciones en cuanto a equidad de género, premia a las organizaciones que ya promueven prácticas equitativas y sirve de acompañamiento para aquellas interesadas en iniciar su camino a la equidad.

También indica que Informe que esta brecha se podría deber a la baja participación de las mujeres en los cargos directivos y de toma de decisiones. Según Grant Thornton (2019), las mujeres ocupan únicamente el 29\% de las posiciones directivas de las empresas y esta cifra sólo ha incrementado 5 puntos porcentuales en los últimos 12 años. En el contexto Latinoamericano también se evidencia esta problemática, pues las mujeres ocupan sólo el $7 \%$ de las posiciones directivas (Deloitte, 2018), sólo el 21\% de las empresas cuentan con una mujer en su máximo cargo directivo (OIT, 2017) y las mujeres ganan $21 \%$ menos que los hombres (OIT, 2018).

En el contexto peruano, estas brechas se ven expresadas de diferentes formas. Por un lado, según la Encuesta Nacional de Empresas (2015) del Instituto Nacional de Estadística e Informática (INEI), las mujeres representan sólo el 33\% del personal ocupado en las empresas peruanas. Además, al observar el tipo de ocupación en el que se encuentran hombres y mujeres, se puede ver que la participación de mujeres en puestos de liderazgo como ejecutivos/as (26.3\%) y propietarios/as (30.8\%) es muy reducida. En cambio, las categorías que tienen mayor participación femenina corresponden a familiares no remunerados $(53.1 \%)$ y practicantes $(42.1 \%)$. Asimismo, sólo $28.2 \%$ de las empresas peruanas son conducidas por mujeres, es decir, 3 de cada 10 líderes de empresa en el país son mujeres y estas se concentran principalmente en las Mypes.

En el Perú, la brecha de ingresos no ha tenido mayores variaciones en los últimos 10 años y se ha mantenido alrededor de un 30\%. Es decir, las mujeres ganan $30 \%$ menos que los hombres en el país. Por otro lado, las mujeres representan el $43.9 \%$ del personal de las organizaciones, tal como se muestra en este gráfico, 
Participación de la mujeres en las organizaciones

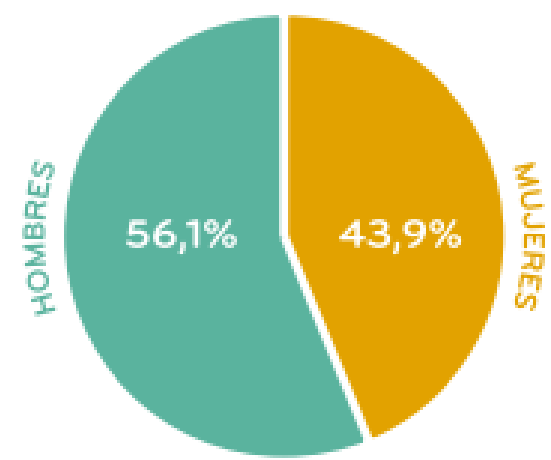

Interesante el concepto de Techo de Cristal, que se menciona en el informe, que menciona la existencia de un techo de cristal, que hace referencia a los obstáculos que enfrentan las mujeres para acceder a cargos directivos, pues se puede ver claramente que la presencia de mujeres va disminuyendo mientras aumenta el nivel jerárquico. En directorio y primer nivel, la presencia de mujeres se reduce a $22 \%$ y $30 \%$ respectivamente. En el siguiente gráfico se muestran los porcentajes de participación de las mujeres por niveles, siendo el primer nivel, los CEO o los órganos más altos de la organización, los del segundo nivel las gerencias de áreas, los de tercer nivel las sub gerencias o jefaturas, cuarto nivel los coordinadores, analistas o equivalentes y el quinto nivel representa todo el personal administrativo por debajo del cuarto nivel.

Tabla 8

Porcentaje de participación de las mujeres en cargos

$$
\text { ¿ Mujeres ì Hombre }
$$

Directorio 22,2\% 70,0\%

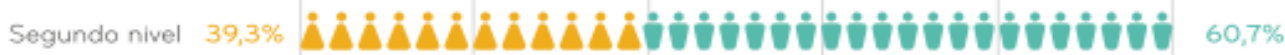
Tercer nivel 42,6\% 56,0\% 51,2\% Personal operativo 28,8\% Personal de ventas 59,2\%

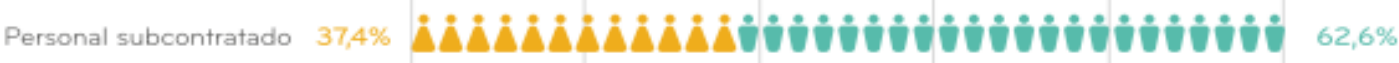
$\begin{array}{llllll}0 \% & 20 \% & 40 \% & 60 \% & 80 \% & 100 \%\end{array}$ 
Interesante también la iniciativa de las organizaciones de formar Comités de equidad de género, lo que al parecer también parecer está incidiendo en la contratación de mujeres para puestos directivos, se menciona que las organizaciones que cuentan con un Comité, contrataron un $34 \%$ más de mujeres en segundo nivel.

Cuando hablan sobre el tema de los roles de los ciudadanos, es importante resaltar lo que destacan que debido a los roles de género que se han impuesto socialmente, las mujeres se ven enfrentadas a una carga desproporcionada asociada a las labores del hogar y del cuidado que limita su desarrollo profesional; las mujeres dedican 20.9 horas más a la semana que los hombres al trabajo doméstico no remunerado en el Perú (MIMP, 2011).

Como conclusiones del Informe se menciona que las empresas que implementan prácticas para promover la equidad de género aún representan a la minoría de organizaciones del país, y hay muchos aspectos en los que todavía resta un camino significante por recorrer, las principales conclusiones del Informe son:

- Las mujeres todavía tienen una representación reducida tanto en los niveles jerárquicos como en las áreas correspondientes a la toma de decisiones dentro de las organizaciones. Debemos implementar diferentes acciones al interior de nuestras organizaciones para convertirnos en agentes de cambio y romper con el techo de cristal.

- Las organizaciones peruanas aún tienen retos pendientes en relación al hostigamiento sexual laboral y la inclusión de la Comunidad LGBTIQ+. Estos son temas que están invisibilizados y es necesario que se empiecen a implementar acciones al interior de las organizaciones para abordar estas problemáticas.

- Al analizar los datos del Ranking PAR en retrospectiva, es esperable que mientras vayamos incrementando el número de organizaciones participantes, los datos se acerquen cada vez más a la realidad del país. Por esto, los porcentajes de implementación de las prácticas dirigidas a promover la equidad suelen verse levemente reducidos. Sin embargo, se resalta que este año presenta los porcentajes más altos de representación de mujeres en cargos directivos.

Entre las prácticas más destacadas con base en la información del Ranking PAR 2019, encontramos las siguientes: 
- El Comité de Equidad de Género constituye un primer paso esencial para las empresas, ya que contribuye a planificar y organizar las acciones dirigidas a la equidad de género y genera responsabilidad y compromiso. De hecho, las empresas que implementan esta práctica cuentan con un mayor número de buenas prácticas para promover la equidad y con un mayor porcentaje de mujeres contratadas para cargos directivos.

- Es fundamental que las empresas empiecen a integrar el enfoque de género en la gestión de la equidad de género, más allá de garantizar solamente igualdad de condiciones, considerando los obstáculos diferenciados a los que se enfrentan hombres y mujeres. Entre estas prácticas se destaca el entrenamiento al equipo de recursos humanos para evitar sesgos y estereotipos de género en los procesos de selección y ascensos, pues esto parece estar relacionado con un mayor porcentaje de mujeres ascendidas a gerencias de área.

- Debido a la carga desproporcionada a la que se enfrentan las mujeres en términos de labores del hogar y del cuidado, es importante que las empresas contribuyan a transformar estos roles por medio de prácticas de flexibilidad dirigidas al cuidado de los/as hijos/ as, fomentando la participación de los hombres en este tipo de labores. Se destaca, por ejemplo, que las organizaciones que cuentan con una licencia de paternidad extendida cuentan con una mayor representación de mujeres en primer y segundo nivel.

En este Ranking, los primeros puestos fueron para la OEFA, Organismo de Evaluación y Fiscalización Ambiental (sector público), Konecta (organizaciones con más de 1.000 colaboradores), Accenture (201 a 1.000 colaboradores), SAP (hasta 200 colaboradores) y laboratorio Takeda (pymes).

\subsection{La importancia del diálogo social en la igualdad de género}

La Organización Internacional del Trabajo. (2019), presenta un Informe Temático "La contribución del diálogo social a la igualdad de género”. Ginebra: OIT, OCDE.

En este informe examina cómo puede el diálogo social arrojar resultados positivos en relación a la igualdad de género en los distintos sectores, ya sea en la economía formal o informal, y explora las circunstancias y los factores que pueden contribuir al cambio transformador.

En su Informe menciona que existe un aumento de la participación de las mujeres en la toma de decisiones y en el diálogo social, indicando que en la actualidad, sólo el 48,5 por ciento de las mujeres, frente al 75 por ciento de los hombres, participan en la fuerza de trabajo (una brecha de género de 26,5 puntos). Cuando las mujeres participan en el 
mercado de trabajo sufren una serie de desventajas, como la discriminación en la contratación y la segregación del mercado laboral, lo que repercute en el tipo y la calidad de los puestos que ocupan. A nivel mundial, las mujeres siguen cobrando un 20 por ciento menos de media que los hombres y, dependiendo de la región, este porcentaje puede llegar a ser de hasta un 40 por ciento.

$\mathrm{Su}$ informe concluye dando recomendaciones clave para las organizaciones de trabajadores y de empleadores y los gobiernos en aras de promover la igualdad de género a través del diálogo social,

\section{Recomendaciones para los gobiernos}

- Promover el diálogo social tripartito y fomentar el desarrollo de políticas nacionales sobre igualdad de género, la obtención de datos desglosados por sexo y la adopción de medidas dirigidas a favorecer la transición de la economía informal a la economía formal.

- Ratificar y aplicar eficazmente los convenios de la OIT sobre libertad sindical, negociación colectiva, igualdad de género y consultas tripartitas.

\section{Recomendaciones para las organizaciones de empleadores}

- Aplicar políticas que apoyen y promuevan la mayor participación y representación de la mujer en el lugar de trabajo, en las organizaciones de empleadores y en las instituciones de diálogo social, inclusive en los puestos de liderazgo.

- Proporcionar apoyo práctico a los empleadores y a las empresas para alentarlos a aplicar estrategias y programas de igualdad de género en el lugar de trabajo, en el marco de las organizaciones de empleadores y en las instituciones de diálogo social.

\subsection{Guía para la igualdad salarial}

Esta guía fue publicada en Dic del 2018 por el Ministerio de la Mujer y Poblaciones Vulnerables y el Ministerio de Trabajo y Promoción del Empleo, resaltando que lograr la igualdad y eliminar la discriminación en el empleo es una tarea fundamental con la que toda la sociedad debe comprometerse, ya que la desigualdad influye en diferentes planos y vulnera la dignidad de las personas, principalmente a las mujeres y los grupos de especial protección. Esta primera guía será complementada con otras que desarrollen metodologías específicas o planteen respuestas frente a la problemática de la discriminación. 
El objetivo de este documento es mostrar las diferencias salariales entre hombres y mujeres que existen en el país, la importancia de reducirlas, los lineamientos normativos existentes, en particular la Ley que prohíbe la discriminación remunerativa entre varones y mujeres (Ley $\mathrm{N}^{\circ} 30709$ ) y la ruta propuesta para implementar medidas que eliminen estas brechas.

Estos gráficos muestran algunos de los resultados de esta guía:

\section{La mayoría de mujeres que se consideran "inactivas" para efectos estadísticos, se dedican a quehaceres del hogar}

\section{Población en Edad de Trabajar (PET)}

Según condición de actividad laboral, 2017

(Porcentaje)

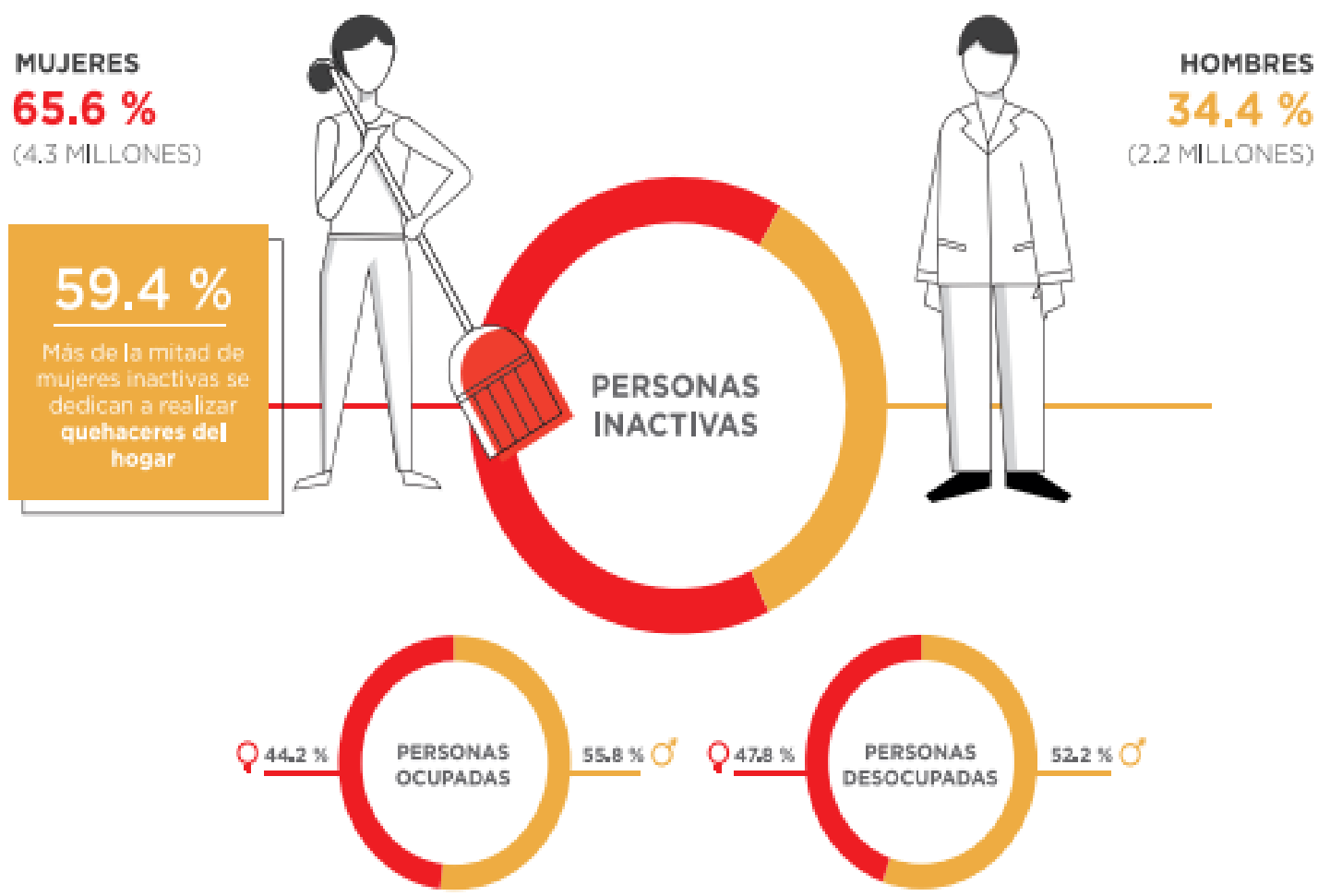

Fuente: NEI - Encuesta Nacional de Hogares sobre Condiciones de Vida y Pobreza, 2017.

Figura 2 Porcentaje de participación de mujeres en edad de trabajar 


\section{Las mujeres que son madres trabajan más y ganan menos}

La maternidad es otro factor que pone en desventaja la situación laboral de las mujeres por dos razones. En primer lugar, las madres trabajadoras tienen doble jornada laboral ( 80 horas semanales), destinando más horas al trabajo no remunerado que al remunerado ${ }^{2}$. En segundo lugar, la brecha salarial entre las mujeres que son madres y las que no, es de $11 \%$ menos en perjuicio de las primeras, siendo especialmente afectadas las madres entre 26 y 30 años de edad y las que viven en Lima Metropolitana.

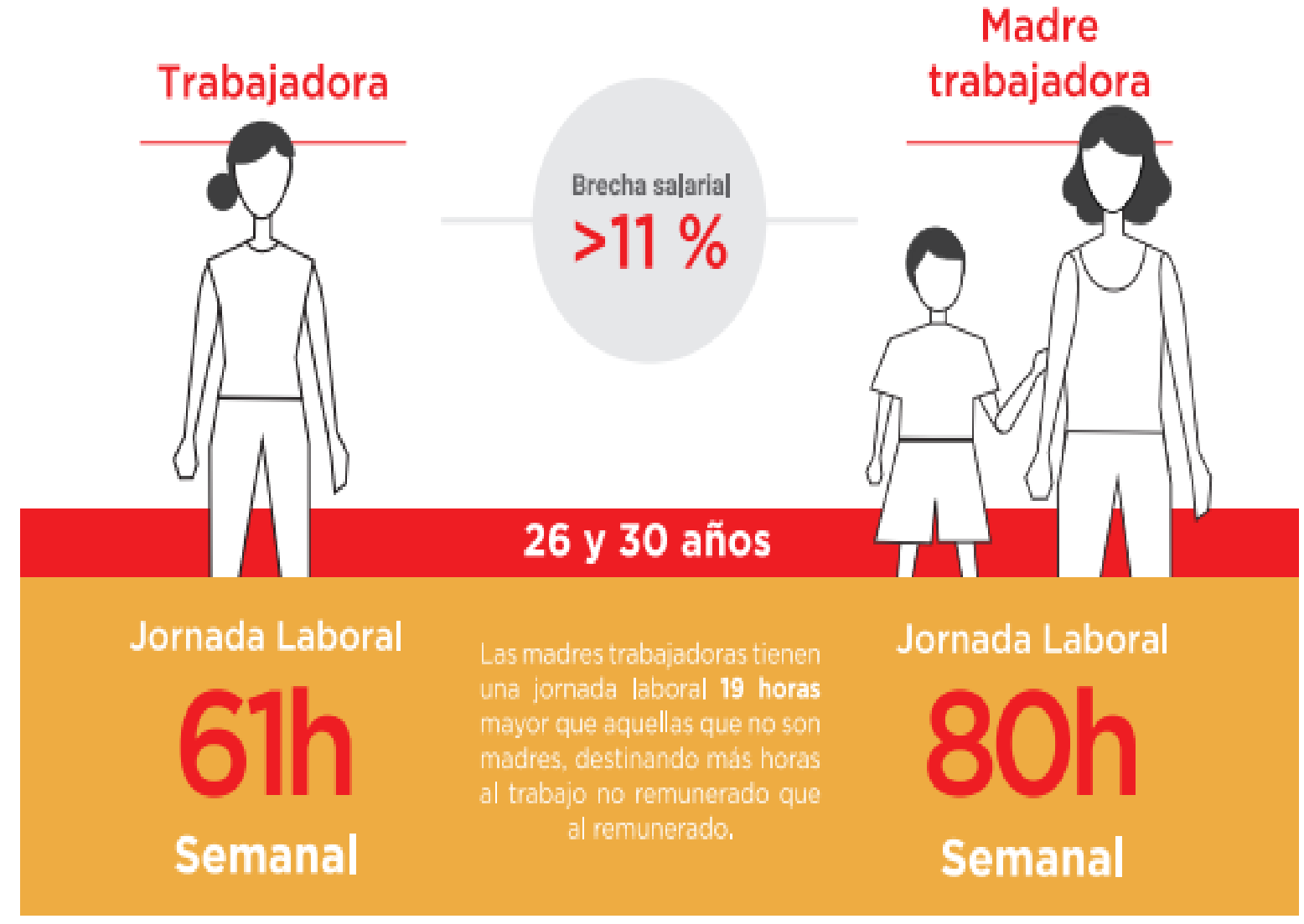

1 Lavado, 2016. Penalzaciones salariaks por maternidad: El ccato de ser madre en d Perú

2El trabajo no remunerado, segin la ENUT, se desglbsa en trabajos de hogar, cuidado de personas y contrbuciones comundes.

Figura 3 Porcentaje de jornada laboral de las mujeres 


\section{La participación de las mujeres es mayor en las ocupaciones menos remuneradas}

PEA Ocupada por sexo Segun categoria ocupacional, 201 ? Porcentaje)

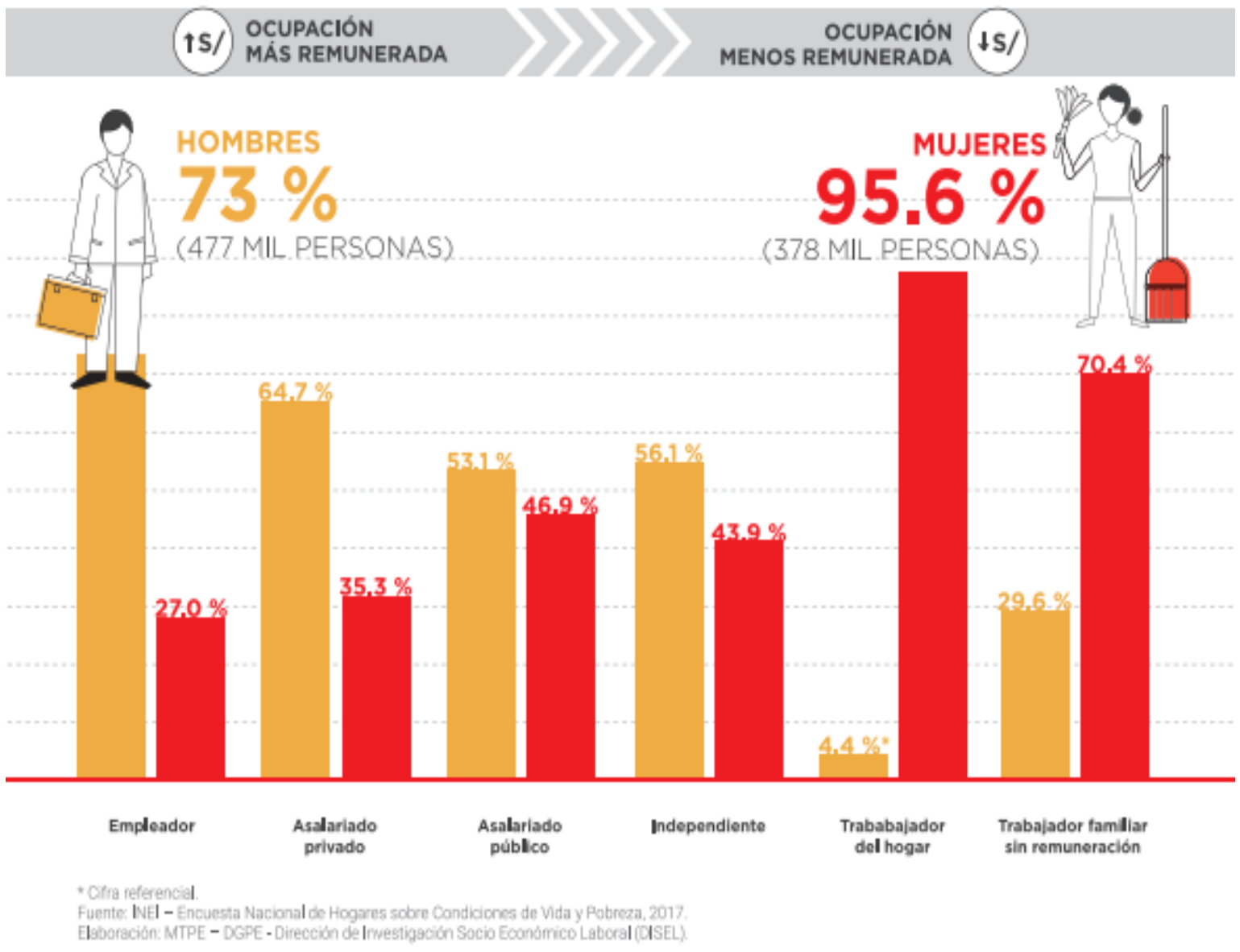

Figura 4 Participación de las mujeres en ocupaciones menos remuneradas 


\section{A nivel nacional, las mujeres perciben menos ingresos que los hombres}

Esta variable de ingreso promedio incluye a has personas empleadoras, asalariadas, indepencientes, trabajadoras no remuneradas y a trabajadoras del hogar.
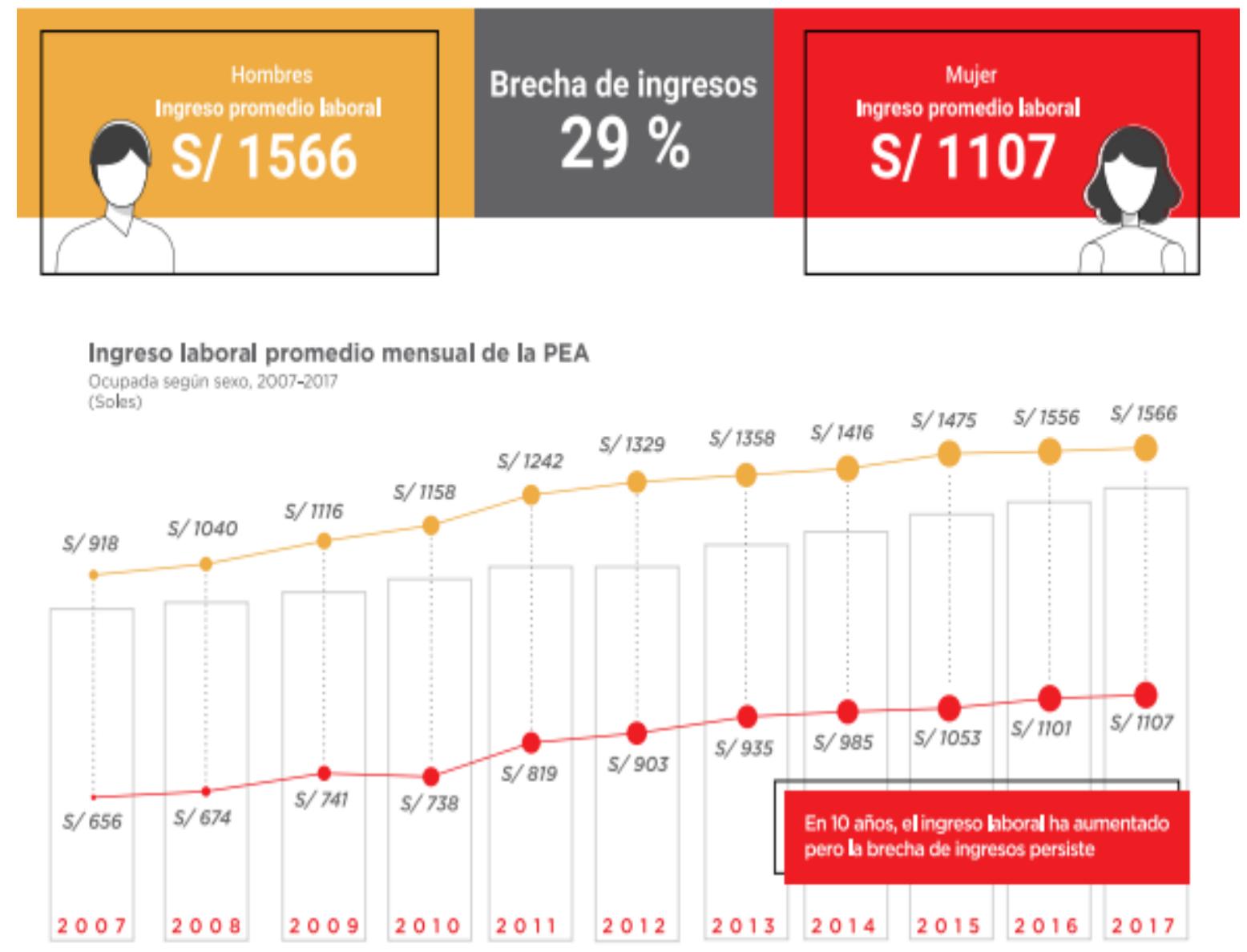

Fuente. INEI - Encuesta Nacional de Hogares sobre Condiciones de Vida y Pobreza, 2017 Elaboración: MTPE - DGDFEST

- Mujer • Hombre

Figura 5 Porcentaje de ingresos de las mujeres a nivel nacional 
5. Las mujeres rurales se encuentran en mayor desvantaja

Rural

$-42 \%$

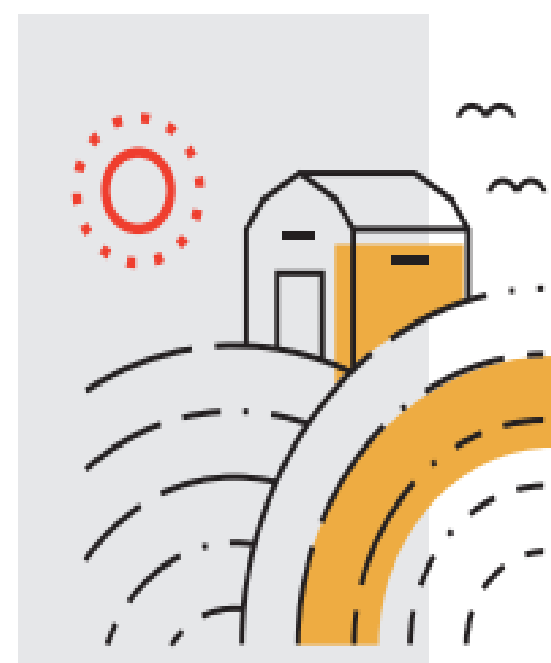

Urbano

$32 \%$

BRECHA

DE INGRESOS

MAYOR EN EL

ÁREA RURAL

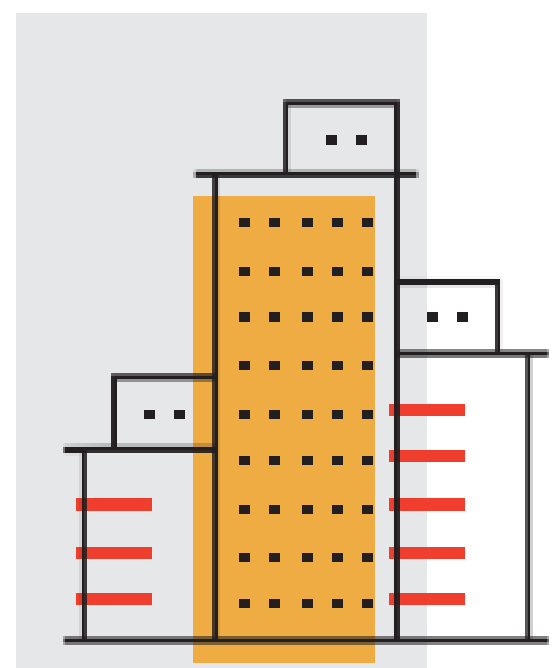

\section{En el área rural}

las mujeres ganan en promedio $42 \%$ menos

que los hombres.

Fuente. INEI - Encuesta Nacional de Hogares sobre Candiciones de Vida y Pobreza, 2017 Elaboracion: MTPE - DCDFSST

Figura 6 Porcentaje de ingresos de las mujeres en los medios rural y urbano 


\section{En el sector privado, la brecha salarial entre hombres y mujeres es mayor}

\section{Hombre}

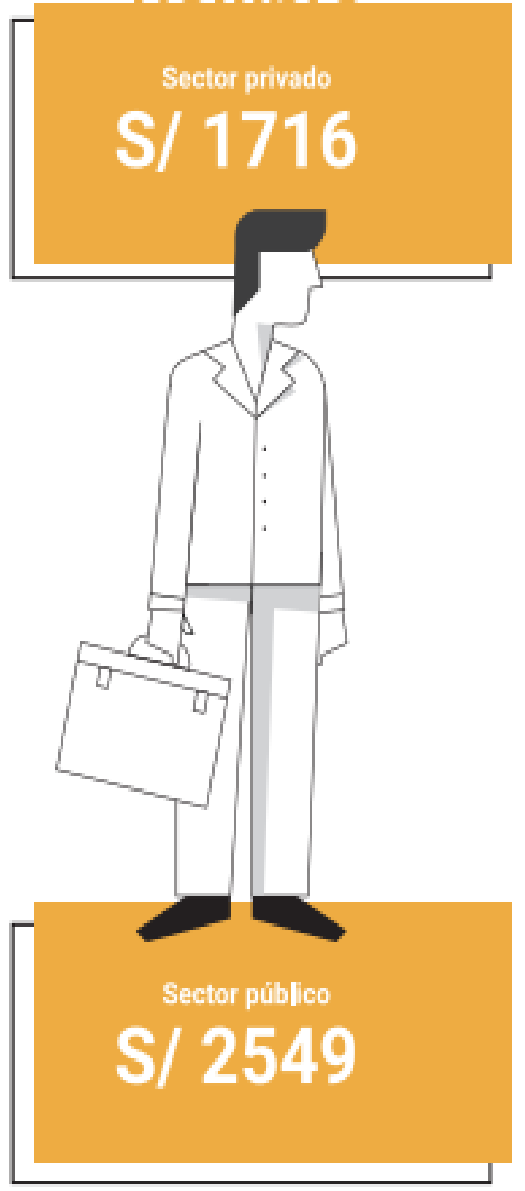

Muier

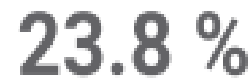

Brecha

salarial

$16 \%$

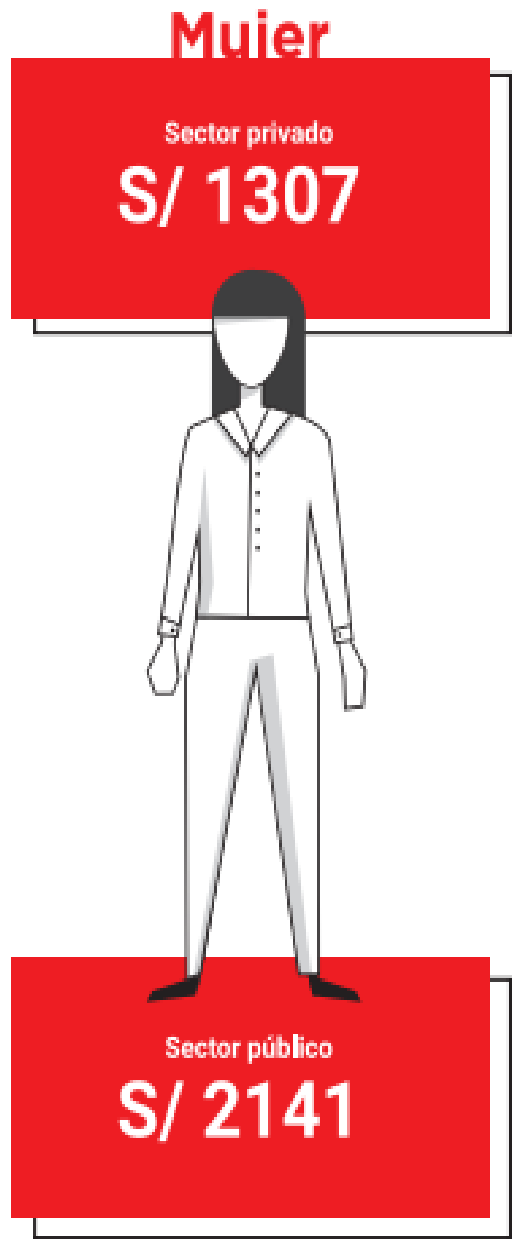

Fuente: NEl - Encuesta Nacional de Hogres sobre Condiciones de Vida y Pobreza, 2017. Elaboracion: MTPE - DGDFSST

Figura 7 Porcentaje de brecha salarial en el sector público 


\section{Donde los salarios son más altos, hay menos mujeres}

Ingreso promedio mensual de la PEA ocupada asalariada privada formal Según rama de actividad económica, 2017

(Solas)

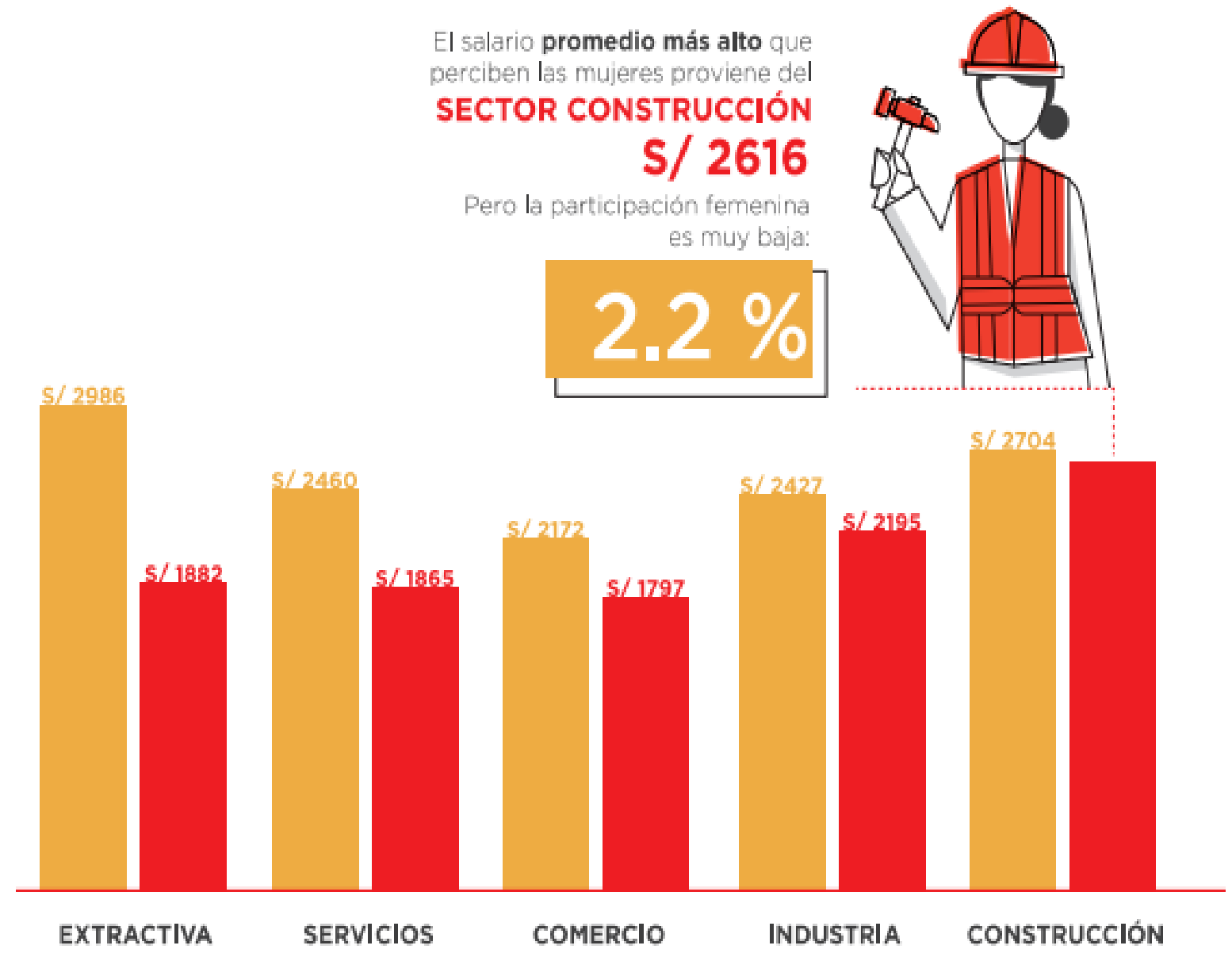

Fuente. INEI - Encuesta Nacional de Hogares sobre Candiciones de Vida y Pobreza, 2017 Eloborncion: MTPE - Xapces:

Figura 8 Porcentaje de brechas salariales entre hombre y mujeres 


\section{La participación de las mujeres en cargos directivos y de toma de decisiones es más baja}

PEA ocupada asalariada privada formal

Segün grupo ocupacional. 2017

(Porcentaje)
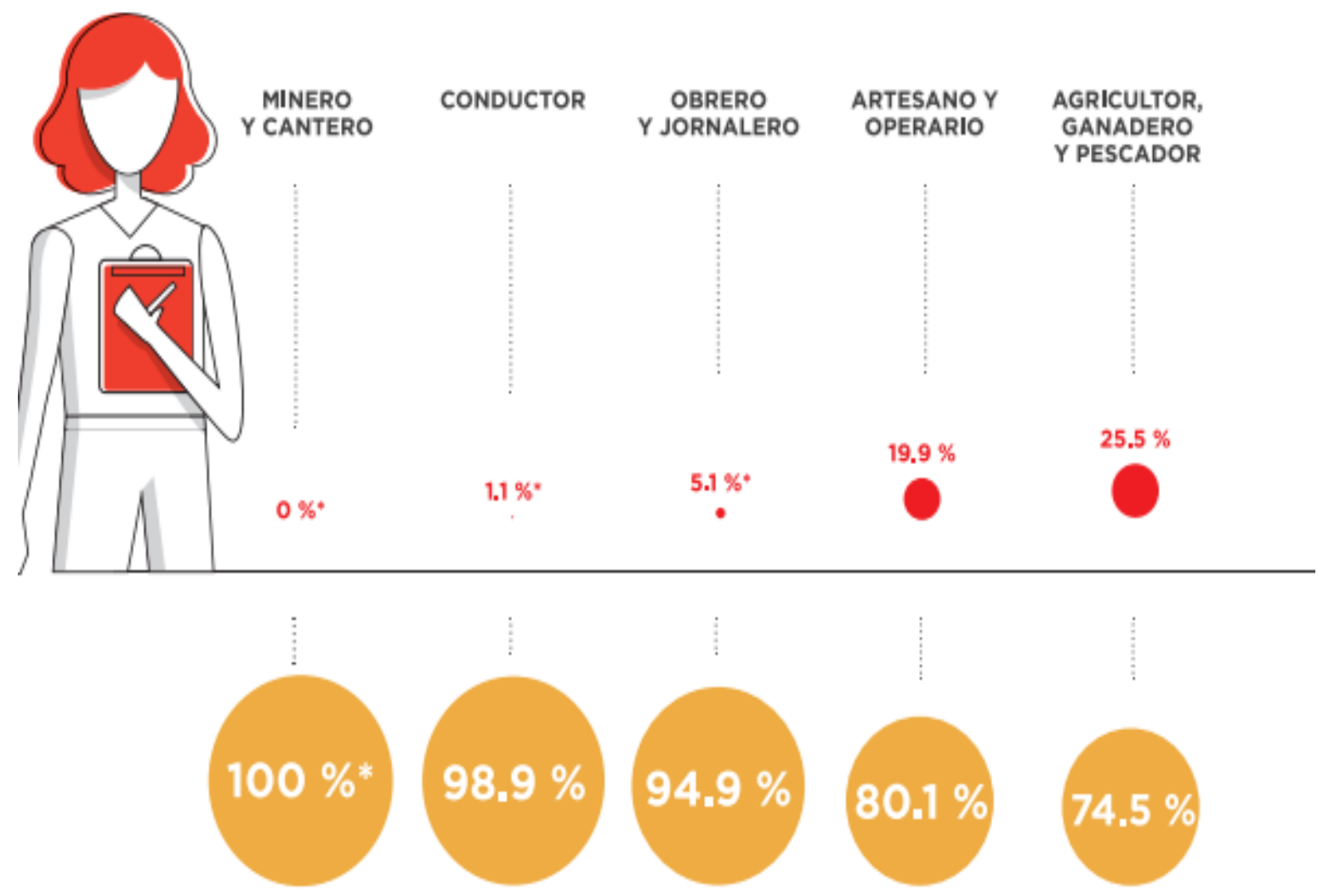

- Clras referenciale:

Fuente: NEI - Encuesta Nacional de Hogares sobre Condiciones de Vida y Pobreza, 2017

Elisboración: MTPE - DGPE. Dirección de Irwestigación Socio Económico Laboral (CISEL)

Figura 9 Porcentaje de las mujeres en cargos directivos

Las pautas que se sugieren para incrementar las medidas de igualdad salarial dentro de las organizaciones son las que se muestran en el siguiente gráfico y su implementación debe estar a cargo de un Comité de igualdad salarial, que garantice la presencia equitativa de hombres y mujeres: 


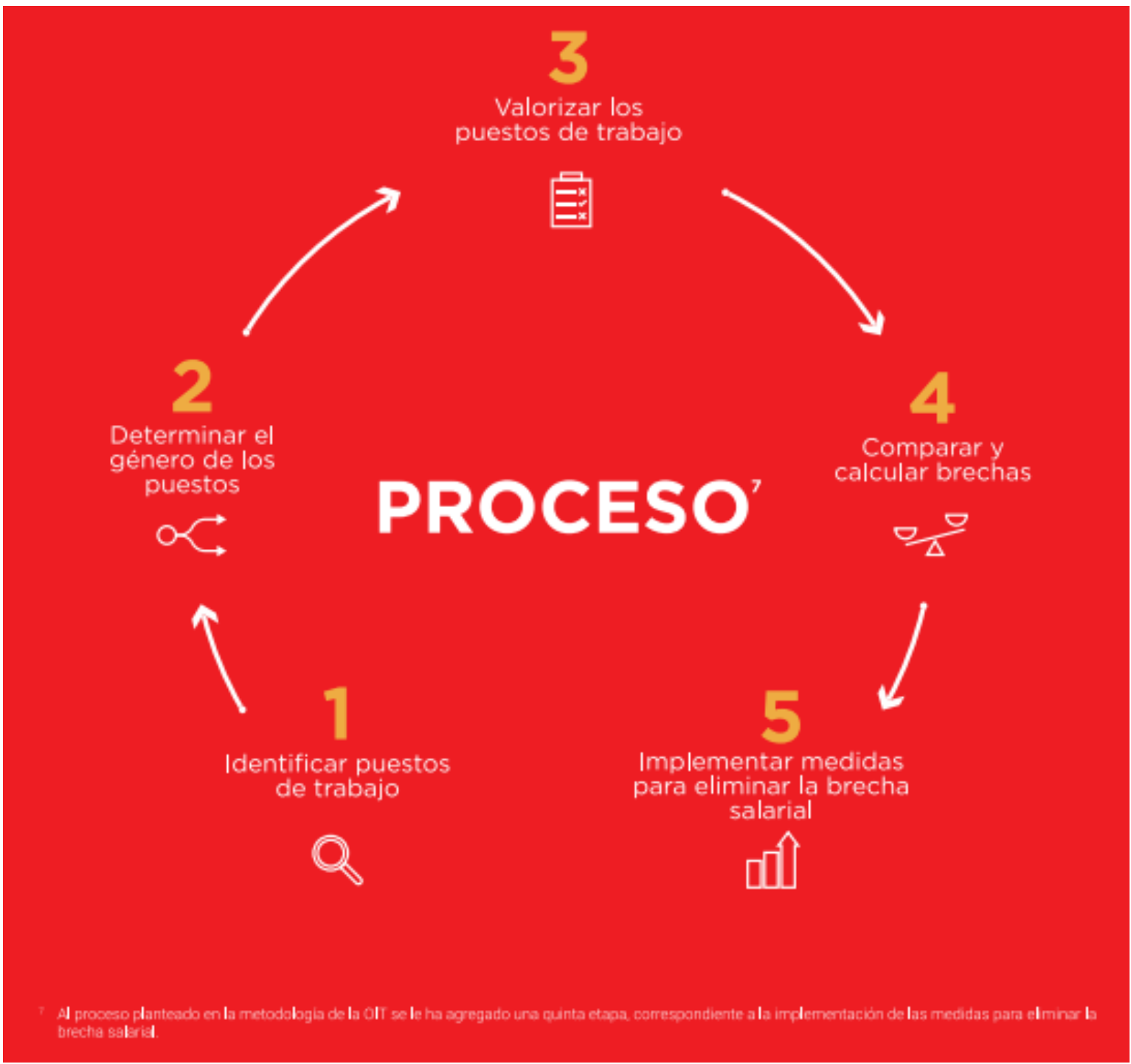

Figura 10 Procedimiento para implementar medidas de igualdad salarial

\subsection{Ley que prohíbe la discriminación remunerativa entre varones y mujeres}

La publicación de la Ley 30709 - Ley que prohíbe la discriminación remunerativa entre varones y mujeres - y su Reglamento pretenden combatir la desigualdad salarial entre varones y mujeres, para ello la norma impone una serie de obligaciones que deberán cumplir las empresas para justificar adecuadamente las diferencias remunerativas o igualar las compensaciones en aquellos casos donde no exista ningún sustento.

"La norma exige que se garantice la igualdad entre hombres y mujeres cuando las empresas decidan implementar planes de formación profesional y de desarrollo de 
capacidades a sus trabajadores. Así mismo, la ley y su reglamento plantean que los empleadores deben cumplir con informar a sus trabajadores de las políticas salariales que se implementen en el centro de trabajo. Dicha comunicación debe realizarse al inicio de la relación laboral o cuando ocurra alguna modificación de dicha política".

Entonces esta Ley prohíbe toda desigualdad remunerativa entre varones y mujeres cuando la diferencia se motiva en el género. La desigualdad es inválida en la medida que sea un trato excluyente e injustificado para las mujeres.

Sin embargo, es totalmente factible que puedan existir diferencias salariales cuando éstas se justifiquen en criterios objetivos y válidos, sin perjuicio de que existan otros, como por ejemplo, antigüedad, experiencia laboral, desempeño, etc.

Por otro lado, la norma exige que se garantice la igualdad entre hombres y mujeres cuando las empresas decidan implementar planes de formación profesional y de desarrollo de capacidades a sus trabajadores.

Asimismo, la Ley y su Reglamento plantean que los empleadores deben cumplir con informar a sus trabajadores de las políticas salariales que se implementen en el centro de trabajo. Dicha comunicación debe realizarse al inicio de la relación laboral o cuando ocurra alguna modificación de dicha política.

Según la Guía para la Igualdad Salarial, Sunafil deberá fiscalizar a las empresas para saber si cumplieron con informar a su personal sobre su política remunerativa, entre otros.

En el Diario La República, del 30 jun. 2019, se menciona que se acabó el plazo concedido y que desde el 1 de julio la Sunafil ya podrá fiscalizar y multar a las medianas y grandes empresas del país que no cumplan con la ley que prohíbe la discriminación remunerativa entre varones y mujeres, publicada en noviembre del 2017.

En ese sentido, la Superintendencia Nacional de Fiscalización Laboral - Sunafil, deberá confirmar con las empresas dos puntos: Primero, verificar que las empresas cuenten con el cuadro de categorías y funciones de los trabajadores, y en segundo lugar, que el empleador 
haya alcanzado a sus trabajadores su política remunerativa donde se especifique en qué condiciones podría ganar más y qué características debería cumplir.

Ambos puntos estuvieron contemplados en la Guía para la Igualdad Salarial publicada en diciembre pasado por el Ministerio de Trabajo y Promoción del Empleo. Al respecto, Germán Lora, abogado laboral, indicó en su momento que desde esa fecha, "fue tiempo suficiente para adecuarse". Las empresas que no cumplan con la guía se considerarían una falta muy grave, la cual se multaría, en el caso de mediana y gran empresa, con hasta 45 UIT (189 mil soles), y en Mypes entre 0,68 UIT (2.856 soles),75 UIT ( 32.550 soles).

\section{LA IGUALDAD DE GÉNERO Y LOS OBJETIVOS DE DESARROLLO SOSTENIBLE (ODS)}

La igualdad entre los géneros no es solo un derecho humano fundamental, sino la base necesaria para conseguir un mundo pacífico, próspero y sostenible. Lamentablemente, en la actualidad, 1 de cada 5 mujeres y niñas entre 15 y 49 años de edad afirmaron haber experimentado violencia física o sexual, o ambas, en manos de su pareja en los 12 meses anteriores a ser preguntadas sobre este asunto. Además, 49 países no tienen leyes que protejan a las mujeres de la violencia doméstica. Asimismo, aunque se ha avanzado a la hora de proteger a las mujeres y niñas de prácticas nocivas como el matrimonio infantil y la mutilación genital femenina (MGF), que ha disminuido en un $30 \%$ en la última década, aún queda mucho trabajo por hacer para acabar con esas prácticas.

Si se facilita la igualdad a las mujeres y niñas en el acceso a la educación, a la atención médica, a un trabajo decente, y una representación en los procesos de adopción de decisiones políticas y económicas, se estarán impulsando las economías sostenibles y las sociedades y la humanidad en su conjunto se beneficiarán al mismo tiempo.

Estableciendo nuevos marcos legales sobre la igualdad de las mujeres en el lugar de trabajo y la erradicación de las prácticas nocivas sobre las mujeres es crucial para acabar con la discriminación basada en el género que prevalece en muchos países del mundo.

\subsection{Algunas metas del objetivo 5 de los ODS}

5.1 Poner fin a todas las formas de discriminación contra todas las mujeres y las niñas en todo el mundo 
5.2 Eliminar todas las formas de violencia contra todas las mujeres y las niñas en los ámbitos públicos y privados, incluidas la trata y la explotación sexual y otros tipos de explotación

5.4 Reconocer y valorar los cuidados y el trabajo doméstico no remunerados mediante servicios públicos, infraestructuras y políticas de protección social, y promoviendo la responsabilidad compartida en el hogar y la familia, según proceda en cada país

\subsection{Asegurar la participación plena y efectiva de las mujeres y la igualdad de oportunidades de liderazgo a todos los niveles decisorios en la vida política, económica y pública}

5.b Mejorar el uso de la tecnología instrumental, en particular la tecnología de la información y las comunicaciones, para promover el empoderamiento de las mujeres

5.c Aprobar y fortalecer políticas acertadas y leyes aplicables para promover la igualdad de género y el empoderamiento de todas las mujeres y las niñas a todos los niveles

\subsection{Datos destacables de los ODS, en referencia al tema de género:}

A nivel mundial, 750 millones de mujeres y niñas se casaron antes de los 18 años y al menos 200 millones de mujeres y niñas en 30 países se sometieron a la mutilación genital femenina (MGF).

$>$ En 18 países, los esposos pueden impedir legalmente que sus esposas trabajen; en 39 países, las hijas y los hijos no tienen los mismos derechos de herencia; y en 49 países no existen leyes que protejan a las mujeres de la violencia doméstica.

$>$ Una de cada cinco mujeres y niñas, incluido el $19 \%$ de las mujeres y las niñas de 15 a 49 años, han sufrido violencia física y/o sexual por parte de una pareja íntima, durante los últimos 12 meses. Sin embargo, en 49 países no existen leyes que protejan específicamente a las mujeres contra tal violencia.

$>$ Si bien en cierto que las mujeres han logrado importantes avances en la toma de cargos políticos en todo el mundo, su representación en los parlamentos nacionales de 23,7\% aún está lejos de la paridad.

$>$ Solo el $52 \%$ de las mujeres casadas o en una unión, toman libremente sus propias decisiones sobre relaciones sexuales, uso de anticonceptivos y atención médica.

$>$ A nivel mundial, las mujeres que poseen tierras agrícolas son solo el 13 por ciento.

> Más de 100 países han tomado medidas para hacer seguimiento de las asignaciones presupuestarias para la igualdad de género.

$>$ Las mujeres en el norte de África acceden a menos de uno de cada cinco empleos remunerados en el sector no agrícola. La proporción de mujeres en empleos remunerados fuera del sector agrícola ha aumentado del 35\% en 1990 al $41 \%$ en 2015. 
$>$ En 46 países, las mujeres ahora ocupan más del 30\% de los escaños en el parlamento nacional en al menos una cámara.

$>$ En Asia Meridional, el riesgo de una niña de casarse en la infancia ha disminuido en más del $40 \%$ desde 2000.

$>$ Las tasas de niñas entre 15 y 19 años sometidas a mutilación genital femenina (mutilación genital femenina) en los 30 países donde se concentra la práctica, han bajado de 1 en 2 niñas en 2000 a 1 en 3 niñas para 2017.

\section{CONVERSANDO SOBRE LA PARTICIPACIÓN POLITICA DE LAS MUJERES}

El 08 de marzo de 2019, la ONPE, realizó un Conversatorio llamado, "Conversando sobre participación política de las mujeres”, donde uno de objetivos fue el de analizar los esfuerzos que se vienen realizando desde el Estado para reducir las brechas de género y empoderar a la mujer en un rol político de mayor protagonismo en el espacio público.

Entre las panelistas se contó con la presencia de la doctora Margarita Díaz Picasso, Abogada, actualmente gerente de Supervisión de Fondos Partidarios (ONPE), especialista en temas de género e inclusión ciudadana, ex directora general de Igualdad de Género y No Discriminación del Ministerio de la Mujer y Poblaciones Vulnerables (MIMP), quien expuso el tema "Avances y retos en la participación de la mujer", ponencia en la cual llama a la reflexión sobre la posición social participativa que tiene la mujer en un ámbito político; además de ello, expuso las dificultades que atraviesan las mujeres en su participación política, concluyendo que solo el ejercicio de una democracia plena impedirá que se atente contra los derechos obtenidos durante las últimas décadas.

Por su parte, Rosario Gamarra Hurtado, Socióloga, especialista en materia electoral y activista social por los derechos de las mujeres, con enfoque de género, dentro de su institución (ONPE), presentó el tema "La experiencia del enfoque de género en la ONPE”. En ella, la ponente se centró básicamente en las iniciativas de proyectos sobre participación que surgieron desde la ONPE y que luego servirían como antecedentes para dar pie a la elaboración de la Ley de Igualdad con Enfoque de Género, para fortalecer la participación de las mujeres en espacios públicos, y que, más adelante, también aportaría a la Ley de Igualdad de Oportunidades.

En el marco de la Ley de Igualdad de Oportunidades, con una serie de normas generadas desde el Estado peruano, en las cuales se promueva que todos los sectores cuenten con instrumentos que institucionalicen la política de promoción de participación de las mujeres en condiciones de igualdad, por lo que se cuenta con una serie de planes, lineamientos y directivas. Por ejemplo, se cuenta con un comité para la 
implementación de políticas de género de la ONPE, presidido por la Gerencia de Información y Educación Electoral, gracias al cual se desarrollan actividades como la participación en mesas de trabajo, en coordinación con el Estado peruano.

Partiendo de ello, el segundo reto sería interpretar cómo se promueve o fortalece la participación política de las mujeres. Como respuesta, el Estado considera el tema estrictamente electoral, situando la participación política solo en los procesos electorales; por ende, la medida más conocida que se ha emitido para la participación de las mujeres es el tema de las cuotas. Si bien se empezó con el $25 \%$ como cuota, actualmente se tiene el $30 \%$, sin embargo, ello no se refleja en mujeres electas, debido a esa sub representación existen medidas como las cuotas. En caso contrario, de no existir, el cuadro sería bajo, numéricamente.

\section{CONCLUSIONES}

Las conclusiones derivadas de este trabajo de investigación son bastantes y diversas, por cuanto hay bastante información y estudios referentes al tema, cada día se muestran nuevos reportes, estadísticas e información actualizada, ya que es un tema con agenda y prioridad mundial.

A continuación se muestran las principales conclusiones de esta investigación:

$\checkmark$ De las alternativas de solución planteadas, y según la ponderación dada a cada una de ellas, las alternativas que quedaron seleccionadas fueron que Servir debe continuar emitiendo propuestas de normativas que regulen horarios de trabajo para Directivos, y otros beneficios o concesiones, a fin de motivar la igualdad de condiciones en las jornadas laborales, y que las ONG como Manuela Ramos, Flora Tristán y/o Asociaciones de mujeres realicen programas, talleres, conferencias, foros, etc, de sensibilización, fortalecimiento y empoderamiento hacia las mujeres.

$\checkmark$ Como menciona el estudio de servir, hoy, en el sector público, prácticamente 5 de cada 10 servidores son mujeres, frente a 3 de cada 10 en el sector privado formal. Sin embargo aún existe un menor número de mujeres que ocupan cargos directivos en relación a los hombres, solo 3 de cada 10 funcionarios y directivos es mujer, registrándose cierta tendencia decreciente desde el año 2011 que, sin embargo, parece haberse revertido en los años 2016 y 2017, en los cuales se incrementó dicha participación. Esto tiene como causa principal que existe un mayor porcentaje de varones que postulan a cargos directivos y/o jefaturales. Dejando en evidencia que un $28 \%$ corresponde a mujeres, mientras que en el caso de varones representan el $72 \%$ de postulantes.

$\checkmark$ Los trabajadores del sector público ganan 14\% más que sus pares mujeres, en el sector privado, ese porcentaje sube a $30 \%$, SERVIR 
$\checkmark$ La participación masculina en el ámbito público y privado es mayor al $45 \%$, pese a que en los últimos años las mujeres tienen un mayor nivel de formación superior

$\checkmark \mathrm{El} 50 \%$ de los emprendimientos tuvo una fundadora.

$\checkmark$ El nivel de rotación de mujeres en sus trabajos es del $18 \%$ y el de los hombres el $25 \%$

$\checkmark$ Uno de cada tres hogares latinoamericanos es liderado por una mujer.

$\checkmark$ El \% de adultos no bancarizados es del $66 \%$ en las mujeres y del $49 \%$ en los hombres, INEI, 2017

$\checkmark$ El síndrome de la doble carga varía en razón de la inversión de tiempo en las actividades remuneradas y no remuneradas. En el caso de las mujeres, se resalta que este síndrome limita, de cierta forma, su desarrollo profesional en altos cargos debido a que el rol relacionado a la familia y a las tareas domésticas es principalmente asumido por ellas. En el caso de la mujer peruana que se inserta al ámbito laboral, existe una diferencia significativa, de más de 24 horas por semana, entre el tiempo que se le dedica al trabajo doméstico no remunerado en relación al dedicado por los hombres. A partir de lo señalado se puede concluir que las mujeres peruanas que se desarrollan como profesionales y además cumplen un rol como responsable de familia, se encuentran ante un desgaste constante, debido a que cuentan con un tiempo limitado que podría ser invertido en otros aspectos relevantes para su desarrollo personal y profesional. Cabe resaltar que este desgaste se incrementa aún más cuando las mujeres asumen cargos directivos y/o jefaturales.

$\checkmark$ Se encontró que existen preferencias de contrataciones respecto al género masculino. Los postulantes hombres reciben en promedio $34 \%$ más llamadas por parte de los empleadores que las mujeres.

$\checkmark$ Actualmente en Perú, no contamos con políticas públicas asentadas que permitan acortar la brecha de equidad de género respecto a cargos Directivos en el Sector Público, recién desde hace un par de años, se está priorizando como política de estado la implementación de normativas, directivas, leyes, políticas y reglamentos en este sentido.

$\checkmark$ Se puede concluir que existe una brecha significativa de postulantes mujeres en cargos directivos y/o jefaturales (44\%) a diferencia de los hombres, esto se puede evidenciar según el estudio realizado por SERVIR.

$\checkmark$ Una de las principales barreras del acceso de mujeres a puestos directivos es la cultura organizacional de las instituciones, la cual estaría basada en estereotipos, de acuerdo a los cuales se valoraría más el trabajo de los hombres en comparación al trabajo de las mujeres.

$\checkmark$ Las mujeres tendrían más dificultades que los hombres para que su trabajo sea valorado y para el desarrollo de su línea de carrera.

$\checkmark$ La equidad de género no se trata sólo de una cuestión de justicia social y derechos humanos, en las investigaciones se destaca que las mujeres deberían ocupar cargos de liderazgo sólo por el hecho de representar a la mitad de la población mundial. Sin embargo, adicionalmente, promover el cierre de brechas de género implica también beneficios económicos para las organizaciones, se observó que en algunos 
caos las empresas que tienen más mujeres en posiciones de liderazgo son más competitivas que aquellas que no las tienen.

$\checkmark$ De 748 encuestas a ejecutivos/as, gerentes/as y asistentes/as en 505 empresas peruanas, las mujeres reportaron los estereotipos de género y la carga familiar como las principales barreras para acceder a cargos gerenciales en sus empresas.

$\checkmark$ Las principales acciones que la mayor parte de las organizaciones ganadoras del Ranking PAR 2019, hecha por Aequales implementan y que representan pasos importantes en el camino a la equidad son, el $100 \%$ destina un porcentaje de su presupuesto a trabajar por la equidad, el $85 \%$ cuenta con un plan de acción de equidad de género, el $60 \%$ cuenta con cuotas de género para cargos directivos, el $100 \%$ brinda capacitaciones para prevenir el hostigamiento sexual labora, entre otras acciones.

$\checkmark$ Cada vez más, líderes empresariales y gobiernos prestan atención a los retornos sociales, económicos y financieros que se obtienen de enfocarse en las mujeres y en la igualdad de género. Desde una perspectiva de desarrollo, la igualdad entre hombres y mujeres contribuye a reducir la pobreza y genera mayores niveles de capital humano para las generaciones futuras.

$\checkmark$ La experiencia internacional muestra que implementar estrategias que promuevan el bienestar de los/as trabajadores/as, especialmente asociadas a permitir una mayor flexibilidad y balance favorecen en gran medida el cierre de brechas laborales entre hombres y mujeres, ya que contribuyen a la conciliación personal-laboral. Por lo tanto, en un empleo en el que no se cuente con disponibilidad de tiempo para encargarse de las tareas de la vida personal, las mujeres tienden a mantenerse en los pisos bajos de la estructura organizacional y, por consiguiente, en las escalas salariales menores (Bertrand, 2017).

$\checkmark$ En el mundo hay actualmente un 50,5\% de hombres y un $49,5 \%$ mujeres - ONU 2018

$\checkmark$ La equidad de género no se trata sólo de una cuestión de justicia social y derechos humanos.

$\checkmark$ Una mayor flexibilidad y balance favorecen el cierre de brechas laborales entre hombres y mujeres

$\checkmark$ Resulta imperante que como personas y como sociedad pongamos en valor la importancia de implementar la Perspectiva de género en las organizaciones y Políticas Públicas, y de asumir y comprometernos con los retos que nos toque, para cerrar las brechas existentes tanto en el servicio civil, como en la sociedad en general.

$\checkmark$ Del Conversatorio de la ONPE, mencionado en el estudio, se concluye que para la práctica de una buena democracia, es preciso no solo incorporar, sino empoderar el papel político de la mujer, en particular dentro de espacios de toma de poder. Así también para desaparecer las brechas de desigualdad en este ámbito es preciso romper con la naturalización de la discriminación, a través de la promoción de una conducta masculina diferente, en donde quede establecido que los derechos que ellos poseen son también los derechos de las mujeres. 


\section{REFERENCIAS}

Autoridad Nacional del Servicio Civil-SERVIR. (2016). Participación de las mujeres en puestos gerenciales: la experiencia del Cuerpo de Gerentes Públicos. Lima

Autoridad Nacional del Servicio Civil -SERVIR. (2019). "La Mujer en el Servicio Civil Peruano 2019”. Lima.

Banco Interamericano de Desarrollo BID. (2015). Empoderamiento económico de las mujeres: Bueno para las mujeres, bueno para los negocios, bueno para el desarrollo. Inter-American Development Bank's, de BID Sitio web: https://publications.iadb.org/handle/11319/7105

Objetivos de Desarrollo Sostenible, también conocidos por sus siglas ODS. Sitio web: https://www.undp.org/content/undp/es/home/sustainable-development-goals.html

Autoridad Nacional del Servicio Civil-SERVIR. (2016). Brecha género en el acceso a puestos directivos: características y principales obstáculos en el ámbito nacional e internacional.

Beltrán Varillas, Cecilia (2014). Políticas públicas de igualdad de oportunidades entre mujeres y hombres: análisis de la viabilidad de diecisiete planes regionales de igualdad de oportunidades en el Perú, en el periodo 2006-2010. Sitio web: http://revistas.pucp.edu.pe/index.php/cienciapolitica/article/view/12539

Instituto Nacional de Estadística e Informática (2016). Perú: "Brechas de Género, 2016: Avances hacia la igualdad de mujeres y hombres". Sitio web: https://www.inei.gob.pe/media/MenuRecursivo/publicaciones_digitales/Est/Lib1388/Libro .pdf

Gerencia de Desarrollo de la Gerencia Pública - Autoridad Nacional del Servicio Civil - SERVIR (2016). Participación de las mujeres en puestos gerenciales: la experiencia del cuerpo de Gerentes Públicos. 
Aequales (2019) Informe de Resultados Ranking PAR 2019 - PERU. Sitio web: https://par.aequales.com/informes/informe-ranking-par-peru-2019.pdf

McKinsey \& Company (2012). Women Matter 2012. Making the Breakthrough. London: McKinsey \& Company. Sitio web: http://www.mckinsey.com/businessfunctions/organization/our-insights/women-matter

Organización Internacional del Trabajo -OIT. (2018). "Perspectivas sociales y del empleo en el mundo": avance global sobre las tendencias del empleo femenino 2018. Ginebra.

Guía para la Igualdad Salarial, (2018) Ministerio de la Mujer y Poblaciones Vulnerables y Ministerio de Trabajo y Promoción del empleo. Sitio web: https://cdn.www.gob.pe/uploads/document/file/263537/Gu\%C3\%ADa-Igualdad-MIMPMTPE.pdf

Organización Internacional del Trabajo. (2019). "La contribución del diálogo social a la igualdad de género". Ginebra: OIT, OCDE, 15 p.

Programa de Naciones Unidas para el Desarrollo (PNUD). Índice de Desarrollo Humano (IDH) 2017. Sitio web: http://hdr.undp.org/sites/default/files/2018 human development statistical update es.pdf 


\section{ANEXOS}

Anexo 1: Mujeres en cargos directivos en el ámbito empresarial en América

Anexo 2: Cuota de género y otras iniciativas en el mundo

Anexo 3: Ficha de datos del Indicador "Porcentaje de cargos directivos ocupados por mujeres".

Anexo 4: Ficha de datos del Indicador "Tasa de incremento anual de cargos directivos ocupados por mujeres"

Anexo 5: Ficha de datos del indicador "Porcentaje de mujeres que postulan a cargos directivos

Anexo 6: Buenas Prácticas a destacar del Ranking PAR 2019 
Anexo 1: Mujeres en cargos directivos en el ámbito empresarial en América

Mujeres en cargos directivos en el ámbito empresarial en América

\begin{tabular}{|c|c|c|c|}
\hline País & $\begin{array}{c}\text { Porcentaje de } \\
\text { empresas con } \\
\text { mujeres en } \\
\text { posiciones ejecutivas } \\
(\%)\end{array}$ & $\begin{array}{c}\text { Porcentaje de } \\
\text { mujeres en } \\
\text { directorio de } \\
\text { empresas cotizadas } \\
\text { en Bolsa }(\%)\end{array}$ & $\begin{array}{l}\text { Porcentaje de } \\
\text { empresas con } \\
\text { participación } \\
\text { femenina en su } \\
\text { propiedad }(\%)\end{array}$ \\
\hline Argentina & 9 & 8 & 38 \\
\hline Bolivia & 22 & --- & 41 \\
\hline Brasil & 18 & 9 & 59 \\
\hline Canadá & --- & 6 & --- \\
\hline Chile & 5 & 5 & 30 \\
\hline Colombia & 12 & --- & 35 \\
\hline Costa Rica & 15 & --- & 44 \\
\hline Ecuador & 17 & --- & 24 \\
\hline El Salvador & 21 & --- & 40 \\
\hline Estados Unidos & --- & 10 & --- \\
\hline Guatemala & 16 & --- & 44 \\
\hline Guyana & 18 & --- & 58 \\
\hline Honduras & 32 & --- & 43 \\
\hline México & 15 & 7 & 26 \\
\hline Nicaragua & 32 & --- & 62 \\
\hline Panamá & 24 & --- & 25 \\
\hline Paraguay & 23 & --- & 52 \\
\hline Perú & 14 & 6 & 29 \\
\hline $\begin{array}{l}\text { República } \\
\text { Dominicana }\end{array}$ & 11 & --- & 30 \\
\hline Surinam & 15 & --- & 18 \\
\hline Uruguay & 19 & --- & 23 \\
\hline Venezuela & 31 & --- & 31 \\
\hline Promedio & 18 & 7 & 38 \\
\hline
\end{tabular}

Fuente: World Economic Forum [WEF] (2014). The global gender gap report 2014. Ginebra, Suiza. En: Women CEO Peru. "Participación de las mujeres en cargos directivos y ejecutivos". XXXVII Asamblea de Delegadas del CIM - Lima, 2016. 


\section{Anexo 2: Cuota de género y otras iniciativas en el mundo}

Tabla 10

Cuota de género y otras iniciativas en el mundo

\begin{tabular}{|c|c|c|}
\hline País & $\begin{array}{c}\text { Cuotas de género } \\
\text { femenino }\end{array}$ & Otras iniciativas \\
\hline Alemania & No tiene cuotas & $\begin{array}{l}\text { El German Corporate Governance Code, aplicable a las } \\
\text { empresas listadas en la bolsa considera } \\
\text { recomendaciones desde el } 2010 \text { para promover la mayor } \\
\text { presencia de mujeres en los directorios, obligando a las } \\
\text { empresas a tener objetivos específicos para lograr esta } \\
\text { mayor representatividad femenina. }\end{array}$ \\
\hline Australia & No existen cuotas & $\begin{array}{l}\text { A partir del } 01 \text { de enero del 2011, las empresas listadas } \\
\text { en la bolsa deben: } \\
\text { a) Adoptar y divulgar públicamente una política de } \\
\text { diversidad. } \\
\text { b) Establecer objetivos para el logro de la diversidad } \\
\text { de géneros y evaluar anualmente dichos objetivos } \\
\text { así como los avances en la consecución de los } \\
\text { mismos. } \\
\text { c) Revelar en cada informe anual los objetivos para el } \\
\text { logro de la diversidad de géneros y los avances en la } \\
\text { consecución de los mismos. } \\
\text { d) Revelar en cada informe anual la proporción de } \\
\text { mujeres entre los empleados de la organización en } \\
\text { su conjunto, en puestos ejecutivos de alto nivel y } \\
\text { otros. }\end{array}$ \\
\hline Bélgica & $\begin{array}{l}\text { Desde el } 2011 \\
\text { considera un } \\
\text { mínimo de } 1 / 3 \\
\text { directoras mujeres } \\
\text { y } 1 / 3 \text { mínimo para } \\
\text { hombres. }\end{array}$ & $\begin{array}{l}\text { En mayo del 2009, el Ministerio de Igualdad de } \\
\text { Oportunidades de la Región Flamenca junto con las } \\
\text { Cámaras de Comercio y del Instituto Belga de } \\
\text { Directores, estableció un programa para promover la } \\
\text { representación de las mujeres en las Juntas Directivas } \\
\text { de las empresas y en puestos de gestión. } \\
\text { El programa incluye coaching a las iniciativas y el } \\
\text { establecimiento de una base de datos pública de }\end{array}$ \\
\hline
\end{tabular}




\begin{tabular}{|c|c|c|}
\hline & & hombres y mujeres candidatos a directores. \\
\hline Canadá & No existen cuotas & $\begin{array}{l}\text { En noviembre del } 2009 \text { se creó el Canadian Board } \\
\text { Diversity Council, con el objetivo de mejorar la } \\
\text { diversidad en los directorios, incluyendo la diversidad } \\
\text { de género. }\end{array}$ \\
\hline \multirow{2}{*}{ China } & \multirow{2}{*}{ No existen cuotas } & $\begin{array}{l}\text { El Code of Corporate Governance for Listed } \\
\text { Companies no menciona el género como deseable o } \\
\text { como un requisito en los antecedentes de los } \\
\text { candidatos a los directorios. }\end{array}$ \\
\hline & & $\begin{array}{l}\text { El Hong Kong's Corporate Govenance Code no } \\
\text { menciona el género como deseable o como un } \\
\text { requisito en los antecedentes de los candidatos a los } \\
\text { directorios. }\end{array}$ \\
\hline $\begin{array}{l}\text { Estados } \\
\text { Unidos }\end{array}$ & No existen cuotas & $\begin{array}{l}\text { En diciembre del 2009, la SEC aprobó una norma que } \\
\text { exige revelar las políticas de las empresas relacionadas } \\
\text { con la diversidad en la identificación de candidatos a } \\
\text { directores, cómo se implementan estas políticas y se } \\
\text { aseguran la efectividad de su aplicación. } \\
\text { Las normas no definen diversidad y permiten que las } \\
\text { propias empresas lo hagan. }\end{array}$ \\
\hline \multirow[t]{2}{*}{ Francia } & \multirow[t]{2}{*}{$\begin{array}{c}\text { Si hay cuotas } \\
\text { obligatorias para } \\
\text { empresas listadas y } \\
\text { no listadas en la } \\
\text { bolsa }\end{array}$} & $\begin{array}{l}\text { A partir del 2017, la proporción de mujeres y hombres } \\
\text { en los directorios no puede ser inferior al } 40 \% \text { en las } \\
\text { empresas que están en la bolsa, o las empresas grandes } \\
\text { (ingresos o activos superiores a } 50 \text { millones de euros o } \\
\text { más de } 500 \text { empleados); si el directorio incluye } 8 \\
\text { personas o menos, la diferencia entre el número de } \\
\text { directores de cada género no puede ser mayor a dos. }\end{array}$ \\
\hline & & Para el periodo entre la actualidad y el 2017 , las \\
\hline
\end{tabular}




\begin{tabular}{|c|c|c|}
\hline & & $\begin{array}{l}\text { empresas listadas en bolsa deben alcanzar una primera } \\
\text { etapa de } 20 \% \text { de participación mínima de hombres y } \\
\text { mujeres. }\end{array}$ \\
\hline India & $\begin{array}{l}\text { Existe una } \\
\text { propuesta para que } \\
\text { las empresas con } 5 \\
\text { o más directores } \\
\text { incluyan por lo } \\
\text { menos una mujer }\end{array}$ & $\begin{array}{l}\text { El India's Corporate Govenance Code no menciona el } \\
\text { género como deseable o como un requisito en los } \\
\text { antecedentes de los candidatos a los directorios }\end{array}$ \\
\hline Noruega & Si tiene cuotas & $\begin{array}{l}\text { Fue el primer país en el mundo en introducir las cuotas } \\
\text { en el } 2005 \text {, con aplicación obligatoria en el 2008. Si los } \\
\text { miembros del directorio tienen } 9 \text { miembros, cada género } \\
\text { debe representar a } 4 \text { directores. Si tiene más de } 9 \\
\text { miembros, cada género debe representar el } 40 \% \text { de los } \\
\text { directores (a partir del } 2008 \text { para empresas públicas). Si } \\
\text { no se cumple, se disuelve la empresa. }\end{array}$ \\
\hline $\begin{array}{l}\text { Nueva } \\
\text { Zelanda }\end{array}$ & No existen cuotas & $\begin{array}{l}\text { Las empresas que cotizan en bolsa se encuentran bajo } \\
\text { una nueva presión para promover la presencia de } \\
\text { mujeres en los directorios. Mark Weldon, jefe ejecutivo } \\
\text { de la bolsa de Nueva Zelanda, informó que la bolsa va a } \\
\text { proponer nuestras normas que exijan a las empresas que } \\
\text { cotizan en bolsa la declaración del número de mujeres y } \\
\text { minorías que tienen en cargos ejecutivos y en los } \\
\text { directorios. }\end{array}$ \\
\hline $\begin{array}{l}\text { Unión } \\
\text { Europea }\end{array}$ & Si hay cuotas & $\begin{array}{l}\text { La Unión Europea está tomando medidas para poder } \\
\text { garantizar la igualdad entre mujeres y hombres, tal } \\
\text { como se menciona en el Tratado de Roma de } 1957 \text {. } \\
\text { La Comisionada, Viviane Reding, ha propuesto una } \\
\text { legislación que exige un } 30 \% \text { en el año } 2015 \text {, ampliando } \\
\text { a } 40 \% \text { en } 2020 \text {. }\end{array}$ \\
\hline
\end{tabular}

Fuente: Women CEO Peru. "Participación de las mujeres en cargos directivos y ejecutivos". XXXVII Asamblea de Delegadas del CIM - Lima, 2016. 
Anexo 3: Ficha de datos del Indicador "Porcentaje de cargos directivos ocupados por mujeres"

Tabla 11

Ficha de datos del \% de cargos directivos ocupados por mujeres

\begin{tabular}{|c|c|}
\hline Nombre del indicador & Porcentaje de cargos directivos ocupados por mujeres \\
\hline Definición & $\begin{array}{l}\text { Es la cantidad de mujeres que en la actualidad ocupan cargos } \\
\text { directivos en las entidades del estado }\end{array}$ \\
\hline $\begin{array}{l}\text { Nivel de desagregación } \\
\text { geográfica }\end{array}$ & Datos a nivel nacional \\
\hline $\begin{array}{l}\text { Línea de base o valor } \\
\text { base }\end{array}$ & $\begin{array}{l}\text { Según estudio de Servir, realizado en año } 2015 \text {, el porcentaje } \\
\text { era de } 30 \% \text { a nivel nacional, de mujeres en cargos directivos }\end{array}$ \\
\hline Valor actual & No existe aún \\
\hline Justificación & $\begin{array}{l}\text { Este indicador nos permite identificar la brecha respecto a los } \\
\text { cargos ocupados por los hombres }\end{array}$ \\
\hline Sentido del indicador & Ascendente \\
\hline $\begin{array}{l}\text { Limitaciones y supuestos } \\
\text { empleados }\end{array}$ & $\begin{array}{l}\text { Existen pocos estudios estadísticos sobre el tema de estudio. } \\
\text { SERVIR es pionero en realizar este tipo de investigación }\end{array}$ \\
\hline $\begin{array}{l}\text { Fórmula o método de } \\
\text { cálculo }\end{array}$ & $\begin{array}{l}100 \% *\left(\mathrm{~N}^{\circ} \text { de mujeres en cargos directivos } / \mathrm{N}^{\circ} \text { de cargos }\right. \\
\text { directivos ocupados })\end{array}$ \\
\hline $\begin{array}{l}\text { Periodicidad de las } \\
\text { mediciones }\end{array}$ & Anual \\
\hline Fuente de datos & $\begin{array}{l}\text { SERVIR } 2015 \text { - ENAHNO PP } 1 \text { y } 4 \text {. The global gender gap } \\
\text { report 2014. Organización Internacional del Trabajo - OIT }\end{array}$ \\
\hline $\begin{array}{l}\text { Órgano } \\
\text { responsable } \\
\text { medición }\end{array}$ & $\begin{array}{l}\text { AUTORIDAD NACIONAL DE SERVICIO CIVIL } \\
\text { SERVIR }\end{array}$ \\
\hline
\end{tabular}




\section{Anexo 4: Ficha de datos del Indicador "Tasa de incremento anual de cargos directivos ocupados por mujeres"}

Tabla 12

Ficha de datos de la tasa de incremento anual de cargos directivos ocupados por mujeres

\begin{tabular}{|c|c|}
\hline Nombre del indicador & $\begin{array}{l}\text { Tasa de incremento anual de cargos directivos ocupados } \\
\text { por mujeres }\end{array}$ \\
\hline Definición & $\begin{array}{l}\text { Es el incremento anual de mujeres que en la actualidad ocupan } \\
\text { cargos directivos en las entidades del estado }\end{array}$ \\
\hline $\begin{array}{l}\text { Nivel de desagregación } \\
\text { geográfica }\end{array}$ & Datos a nivel nacional \\
\hline $\begin{array}{l}\text { Línea de base o valor } \\
\text { base }\end{array}$ & $\begin{array}{l}\text { Según estadísticas de Servir, en el año } 2009 \text { el porcentaje de } \\
\text { mujeres en cargos directivos era del 11\%. }\end{array}$ \\
\hline Valor actual & $\begin{array}{l}\text { Según estadísticas de Servir, al el año } 2016 \text { el porcentaje de } \\
\text { mujeres en cargos directivos es del } 24 \% \text {. }\end{array}$ \\
\hline Justificación & $\begin{array}{l}\text { Este indicador nos permite identificar la tendencia y la tasa de } \\
\text { incremento, así como también la brecha respecto a los cargos } \\
\text { ocupados por los hombres }\end{array}$ \\
\hline Sentido del indicador & Ascendente \\
\hline $\begin{array}{l}\text { Limitaciones y supuestos } \\
\text { empleados }\end{array}$ & Ninguno \\
\hline $\begin{array}{l}\text { Fórmula o método de } \\
\text { cálculo }\end{array}$ & $\begin{array}{l}100 \% *\left(\mathrm{~N}^{\circ} \text { de mujeres en cargos directivos/ } \mathrm{N}^{\circ} \text { de cargos }\right. \\
\text { directivos ocupados) }\end{array}$ \\
\hline $\begin{array}{l}\text { Periodicidad de las } \\
\text { mediciones }\end{array}$ & Anual \\
\hline Fuente de datos & $\begin{array}{l}\text { Estadísticas de base de datos de Gerentes Públicos asignados a } \\
\text { entidades del Estado - AUTORIDAD NACIONAL DEL } \\
\text { SERVICIO CIVIL - SERVIR }\end{array}$ \\
\hline $\begin{array}{llr}\text { Órgano } & \text { y } & \text { entidad } \\
\text { responsable } & \text { de } & \text { la } \\
\text { medición } & & \end{array}$ & $\begin{array}{l}\text { AUTORIDAD NACIONAL DE SERVICIO CIVIL } \\
\text { SERVIR }\end{array}$ \\
\hline
\end{tabular}




\section{Anexo 5: Ficha de datos del indicador "Porcentaje de mujeres que postulan a cargos directivos}

Tabla 13

Ficha de datos del porcentaje de mujeres que postulan a cargos directivos

\begin{tabular}{|c|c|}
\hline Nombre del indicador & Porcentaje de mujeres que postulan a cargos directivos \\
\hline Definición & Porcentaje de mujeres que postulan a cargos directivos \\
\hline $\begin{array}{l}\text { Nivel de desagregación } \\
\text { geográfica }\end{array}$ & Datos a nivel nacional \\
\hline $\begin{array}{l}\text { Línea de base o valor } \\
\text { base }\end{array}$ & $\begin{array}{l}\text { Al } 201528 \% \text { de postulaciones a cargos directivos } \\
\text { corresponde a mujeres }\end{array}$ \\
\hline Valor actual & No existe aún \\
\hline Justificación & $\begin{array}{l}\text { Este indicador nos permite identificar la participación de } \\
\text { mujeres a procesos de selección para directivos públicos }\end{array}$ \\
\hline Sentido del indicador & Ascendente \\
\hline $\begin{array}{l}\text { Limitaciones y supuestos } \\
\text { empleados }\end{array}$ & $\begin{array}{l}\text { Existen pocos estudios estadísticos sobre el tema de } \\
\text { estudio. SERVIR es pionero en realizar este tipo de } \\
\text { investigación }\end{array}$ \\
\hline $\begin{array}{l}\text { Fórmula o método de } \\
\text { cálculo }\end{array}$ & $\begin{array}{l}100 \% *\left(\mathrm{~N}^{\circ} \text { de mujeres postulantes a cargos directivos/ } \mathrm{N}^{\circ}\right. \\
\text { personas que postulan a cargos directivos })\end{array}$ \\
\hline $\begin{array}{l}\text { Periodicidad de las } \\
\text { mediciones }\end{array}$ & Anual \\
\hline Fuente de datos & $\begin{array}{l}\text { Base de datos de selección de gerentes públicos, SERVIR } \\
2015\end{array}$ \\
\hline $\begin{array}{l}\text { Órgano y } \quad \text { entidad } \\
\begin{array}{l}\text { responsable } \\
\text { medición }\end{array}\end{array}$ & $\begin{array}{l}\text { AUTORIDAD NACIONAL DE SERVICIO CIVIL } \\
\text { SERVIR }\end{array}$ \\
\hline
\end{tabular}




\section{BUENAS PRÁCTICAS A DESTACAR}

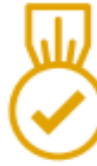

Mejor práctica laboral en el sector privado del Ranking PAR de Equidad de Género en las Organizaciones 2019:

SUPERMERCADOS PERUANOS, por su proceso de selección semiciego diseñado con el objetivo de reducir los estereotipos de género sobre determinadas posiciones y fomentar la diversidad.

Mejor práctica innovadora con enfoque de género del Ranking PAR de Equidad de Género en las Organizaciones 2019:

FINANCIERA CONFIANZA, por su producto de crédito Palabra de Mujer (PDM), el cual está dirigido a mujeres con el objetivo de impulsar su autonomia económica y la generación de ingresos.

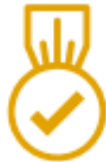

Mejor práctica laboral en el sector público del Ranking PAR de Equidad de Género en las Organizaciones 2019:

MINISTERIO DE RELACIONES EXTERIORES, por la elaboración de un plan de actividades que incluye la realización de campañas de prevención sobre trata de personas y eliminación de la violencia contra las mujeres a través de 116 oficinas consulares distribuidas en todo el mundo.

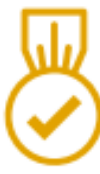

Mejor pieza de comunicación inclusiva del Ranking PAR de Equidad de Género en las Organizaciones 2019:

TELEFÓNICA, por su campaña Igualdad en la cancha, la cual, en alianza con Sisy Quiroz (cofundadora de Ligas Femeninas de Fútbol 7), promueve la equidad y cuestiona los estereotipos de género asociados a roles tradicionalmente masculinos.

Figura 11 Buenas Prácticas a destacar en el tema de igualdad de género 